\title{
A Pilot Study on Structural Responses of Normal Concrete-UHPC Composite Bridge Decks $w / w o$ Rebars through an Experimental-Numerical Approach
}

\author{
Siqi Yuan, ${ }^{1,2}$ Zhao Liu $\mathbb{D}^{1,3}$ Teng Tong, ${ }^{1,3}$ and Chung C. Fu ${ }^{2}$ \\ ${ }^{1}$ School of Civil Engineering, Southeast University, Nanjing, China \\ ${ }^{2}$ Department of Civil and Environmental Engineering, University of Maryland, College Park, MD, USA \\ ${ }^{3}$ Key Laboratory of Concrete and Prestressed Concrete Structures of Ministry of Education, Southeast University, Nanjing, China
}

Correspondence should be addressed to Zhao Liu; mr.liuzhao@seu.edu.cn

Received 21 June 2020; Revised 18 July 2020; Accepted 31 July 2020; Published 30 August 2020

Academic Editor: Venu G. M. Annamdas

Copyright (c) 2020 Siqi Yuan et al. This is an open access article distributed under the Creative Commons Attribution License, which permits unrestricted use, distribution, and reproduction in any medium, provided the original work is properly cited.

Ultra-high-performance concrete (UHPC) is already gaining in-field applications in bridge deck rehabilitation. On the other aspect, an innovative NC-UHPC composite deck system was motivated to promote accelerated bridge construction (ABC) implementation of a newly built bridge, of which the precast UHPC substrate serves as the formwork for the cast-in-place NC overlay. Performance characterizations were investigated by loading five decks, of various UHPC thickness and $w / w o$ longitudinal or transverse rebars. Their effects on the composite decks' failure patterns and load-deflection curves were quantitatively analyzed. Besides, digital image correlation (DIC) technique was adopted to adequately capture their damage evolutions. Moreover, analytical solutions for predicting a composite deck's flexural and shear strengths are tentatively derived. Finally, 3D finite element (FE) models are developed within ATENA framework, capable of embracing the NC-UHPC interface's behaviors. Numerical predictions agree well with the experimental results and can benefit further researches evolving a NC-UHPC composite deck system.

\section{Introduction}

Ultra-high-performance concrete (UHPC) presents extraordinary mechanical properties when compared to normal concrete (NC): greater compressive and tensile strengths, excellent toughness, and durability, to name a few $[1,2]$. In recent years, UHPC has gained significant momentum in terms of its utilization in highway and pedestrian bridges $[3,4]$, in the US, New Zealand, South Korea, Japan, Australia, and China. Nevertheless, the expensive initial capital cost (around 3 4 times that of NC) hinders the wider application of full-depth UHPC members, e.g., UHPC precast waffle deck panels [5]. Specified at a bridge deck, the merits of minimizing deck cracking and maintaining long-term durability render UHPC attractive in retrofitting deteriorated NC decks [6]. With a thin UHPC overlay, an as-built bridge deck's strength and durability can be effectively upgraded $[7,8]$.
Contrary to as-built bridges already in service, there are still enormous demands for newly built highway and urban bridges. For these bridges, accelerated bridge construction $(A B C)$ technique, usually combined with precast members, provides an attractive solution to accelerate the construction work, decrease the in-field labor cost, reduce environmental or traffic disturbances, and enhance quality control [9]. Many scholars and engineers are devoted to the $\mathrm{ABC}$ implantation of bridge decks. Aaleti et al. [10] experimentally evaluated the structural behaviors of precast waffle bridge decks constructed with full-depth UHPC, as well as connections. Honarvar et al. [11] in field tested the performance and optimized the design of UHPC waffle decks. In addition, Fehling et al. [12] deigned the first hybrid UHPC-steel bridge. Graybeal [13] adopted UHPC to connect the precast NC bridge deck panels, which was further enriched by other scholars $[5,14,15]$. 
Realizing that UHPC could benefit the ABC implementation of a newly built bridge deck, a NC-UHPC composite bridge deck concept was motivated by underlying a UHPC substrate below a NC slab (see Figure 1). The following advantages are foreseen: (a) both UHPC and NC belong to cementitious material family, enabling compatibility at the interface; (b) the system provides a cost-effective solution by reducing the amount and weight of UHPC in comparison to a full-depth counterpart; (c) the UHPC substrate serves as the formwork for cast-in-place NC overlay and can promote the $\mathrm{ABC}$ implementation of bridge decks; and (d) the system takes advantages of both NC's compressive strength and UHPC's agreed post-peak behaviors on one hand, and the cracking and maintenance cost could be apparently alleviated on the other hand.

However, a performance characterization of the composite deck system is indispensable to make this concept a reality for field applications. To this end, five specimens were prepared and loaded to investigate their static behaviors, and various design parameters were deliberatively taken into account, including thickness of UHPC substrate, $w / w o$ longitudinal rebars, and $w / w o$ stirrups. Digital image correlation (DIC) technique was employed, which was an optical, non-contacting measuring technique enabling the possibility to detect displacement and deformation fields at a specimen's surfaces. Besides, analytical solutions are derived for predicting a composite deck's flexural and shear strengths. At the end, 3D finite element (FE) models are constructed to realistically capture their static behaviors, with the tested NC-UHPC interface properties being incorporated.

Through the research in this paper, the failure patterns are determined in this innovative NC-UHPC composite deck with different reinforcement situation and UHPC thickness. Then, the analytical solutions to predict the composite deck's strength are derived, either flexural or shear strengths. At last, a 3D FE modeling method within the ATENA framework is constructed for composite decks.

\section{Experimental Protocol}

2.1. Specimen Design and Fabrication. Dimensions and reinforcing details for the five NC-UHPC composite specimens (U50, U60, U70, U60-LS, and U60-S) are summarized in Table 1. All these five decks had an indicial $250 \times 150 \mathrm{~mm}$ (width $\times$ height) cross section. Identical reinforcing details were applied to the composite deck U60-LS, having the $60 \mathrm{~mm}$ thick UHPC substrate versus the $90 \mathrm{~mm}$ thick NC overlay (see Figure 2(a)). Of special attention were the two roles of the stirrups: increasing a specimen's overall shear strength and enhancing bond strength between the UHPC and NC layers. Anchored at UHPC's enhanced tensile strength and post-cracking ductility [16], as a contrast, specimens U50, U60, and U70 tentatively and deliberatively removed conventional longitudinal and transverse rebars (see Figure 2(b)). In addition, merely the U-shaped stirrups crossing the NC-UHPC interface were adopted for specimen $\mathrm{U} 60-\mathrm{S}$, in consideration of enhancing the bond strength (see Figure 2(c)).
To mimic the ABC implementation of a bridge deck, the UHPC substrate was fabricated (see Figure 3(a)). After 28day curing under natural conditions, the NC overlay was cast and the UHPC substrate served as the bottom formwork (see Figure 3(b)). The bond strength of NC-UHPC interface, no doubt, affects overall behaviors of the composite decks [17]. To ensure the proper bond strength, the UHPC substrate was submerged into water for more than 10 hours before casting the NC overlay. Moreover, no roughness treatment on the UHPC surface was implemented [12].

2.2. Material Properties. Mix proportions of UHPC are presented in Table 2 . The fiber used in this paper is straight steel fiber with $20 \mathrm{~mm}$ length and $0.2 \mathrm{~mm}$ diameter. The steel fibers were randomly distributed and took around $2 \%$ volume fraction. Strict curing condition was conventionally required to obtain rapid strength development; e.g., the curing was maintained at $20^{\circ} \mathrm{C}$ for $12 \sim 48$ hours, followed by steam curing at $90^{\circ} \mathrm{C}$ for another $24 \sim 72$ hours [18]. Nevertheless, the simplified curing with water-cover sheet subject to room temperature was adopted for the UHPC substrate to ease the specimen fabrication, although accompanied with some early-age strength loss.

Three $100 \times 100 \times 100 \mathrm{~mm}$ UHPC cubes were compressed to failure and the mean cubic strength was 129.7 MPa, which was equivalent to the mean cylindric strength of $102.5 \mathrm{MPa}$. The $40.1 \mathrm{GPa}$ elastic modulus was obtained for UHPC. Flexural strengths of UHPC were obtained with three $100 \times 100 \times 400 \mathrm{~mm}$ prisms (see Figure 4), which were $13.8 \mathrm{MPa}$. In addition, the mean cylindric strength was $40.9 \mathrm{MPa}$ for the C50 normal concrete.

Similarly, three HRB400 rebars were tensioned to failure and the measured stress-strain relationship is illustrated in Figure 5. The mean yield strength $400 \mathrm{MPa}$ and ultimate tensile strength $540 \mathrm{MPa}$ were obtained (see Table 3).

2.3. Test Setup and Loading Scheme. Four-point bending test was performed on the specimens. The clear span between the two steel rollers was $1000 \mathrm{~mm}$ and the distance between the two loading points was set as $400 \mathrm{~mm}$ (see Figure 6(a)). Force-control loading scheme was conducted. Three linear variable differential transformers were set to measure the displacement, with two being placed at the supports and one at the midspan. Five strain gauges were attached on the decks to evaluate the strain distribution (see Figure 6(b)). Besides, DIC (digital image correlation) system was also equipped to track the damage propagation and display the overall strain field of the decks $[19,20]$ (see Figure 6(a)).

\section{Characterization of NC-UHPC Bond Strength}

As one of the cementitious materials, UHPC is reported to be compatible with NC, even if without the stirrups crossing the interface [16]. To quantitatively evaluate the bond strength, nine specimens were fabricated for the slant shear test, with three different interfacial angles (namely, $50^{\circ}, 60^{\circ}$, and $70^{\circ}$ ) being taken into account (see Figure 7 and Table 3 ). 


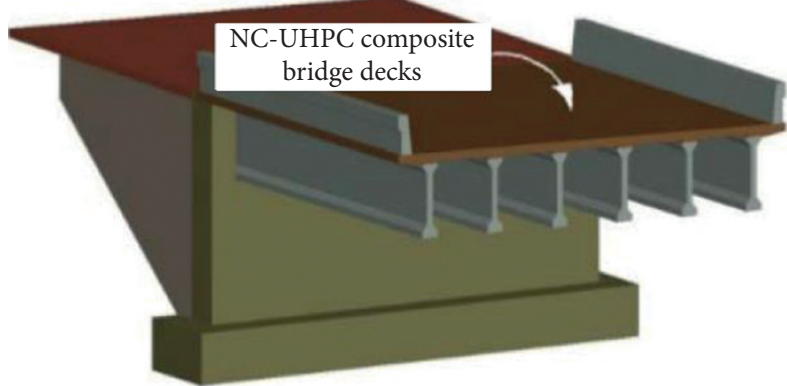

(a)

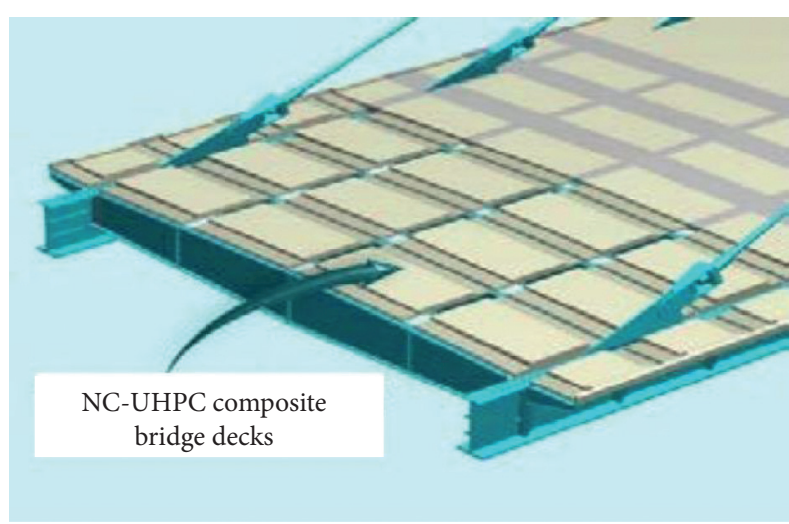

(c)

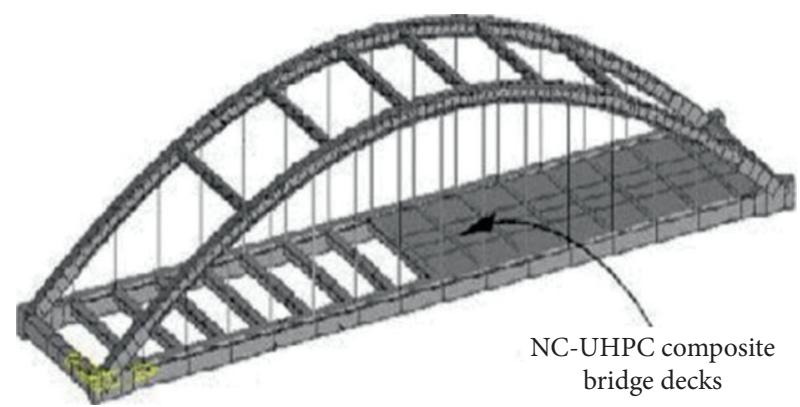

(b)

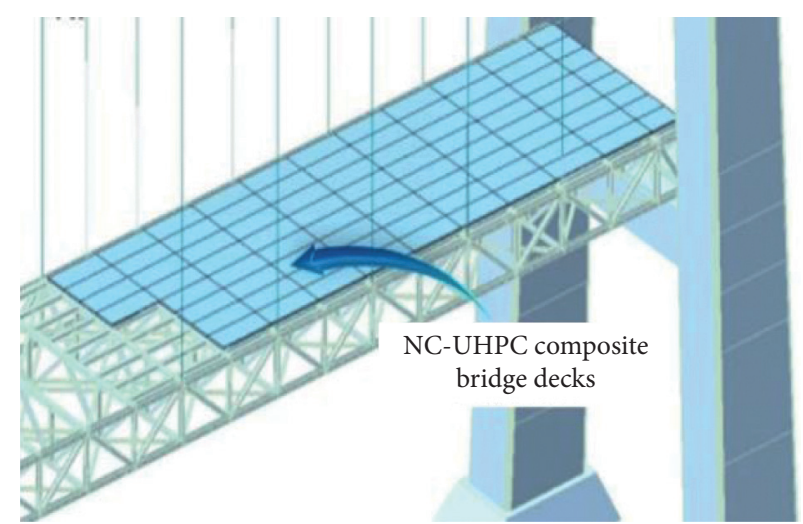

(d)

Figure 1: Probable application for NC-UHPC composite bridge decks. (a) Beam bridge. (b) Arch bridge. (c) Cable stayed bridge. (d) Suspension bridge.

TABLE 1: Dimensions and reinforcing details.

\begin{tabular}{lcccc}
\hline Specimens & \multicolumn{2}{c}{ Thickness $(\mathrm{mm})$} & \multicolumn{2}{c}{ Rebars } \\
& NC overlay & UHPC substrate & Longitudinal & Transverse \\
\hline U60-LS & 90 & 60 & $\$ 12$ & \\
U50 & 100 & 50 & - & \\
U60 & 90 & 60 & - \\
U70 & 80 & 70 & - & $\$ 150 @ 150$ \\
U60-S & 90 & 60 & \\
\hline
\end{tabular}

The UHPC and the NC were from the same batch of the decks and their interface treatments were identical to the process mentioned in Section 2.

Most specimens suffered from the interface failure, subject to axial compressive force (see Figure 7). The shear strength of the interface is evaluated as the maximum shear force divided by the area, as follows:

$$
\tau_{\text {test }}=\frac{P \sin \alpha}{A},
$$

where $\tau_{\text {test }}$ is the tested interface shear strength; $P$ is the peak force; and $A$ is the area of the slant interface. The measured $P$ and $\tau_{\text {test }}$ for the nine specimens are summarized in Table 4 .

On the other aspect, predicted shear strength $\tau_{u}$ from [21], for conventional NC-NC interface without rebars, is calculated as

$$
\tau_{u}=c+\frac{\mu P}{A},
$$

where $c$ is the coefficient for the adhesive bond and $\mu$ is the friction coefficient.

According to the slant shear test, coefficients $c=1.95 \mathrm{MPa}$ and $\mu=0.9$ were determined by the least-square fitting method. The covariance for the fitting result was 29.56 , and the correlation coefficient was 0.981 , indicating the agreed fitting results with equation (2). Note that the recommended value of $c$ is within 1.7 2.8 and $\mu$ is within 1.0 1.4 [21]. The comparison of the tested and the fitted interface shear strengths, namely, $\tau_{\text {test }}$ and $\tau_{u}$, is illustrated in Figure 8 and Table 4.

\section{Damage Evolutions and Test Results}

Damage evolutions and relationships between external loading and midspan deflection are described, which are categorized into (1) decks with longitudinal and transverse rebars, (2) composite decks without any rebars, and (3) composite decks with merely transverse rebars. 


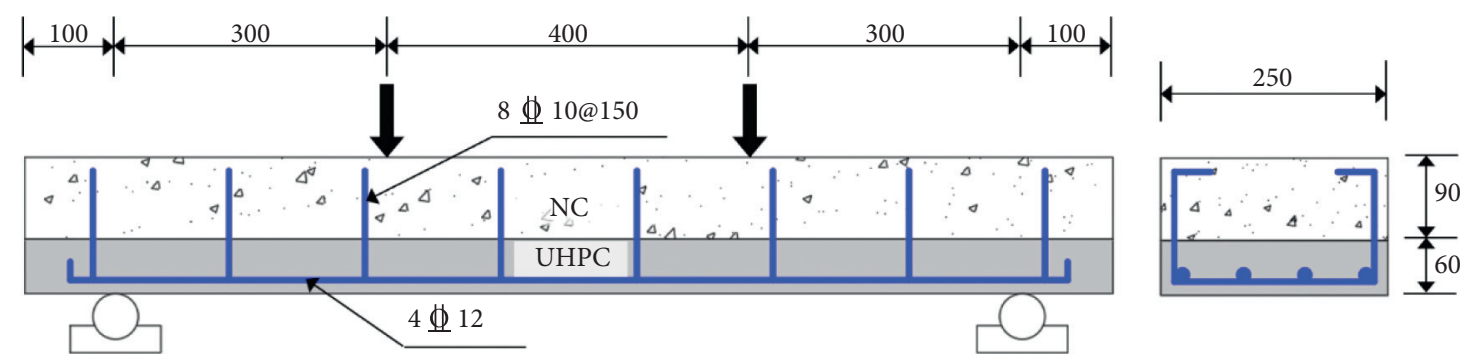

(a)
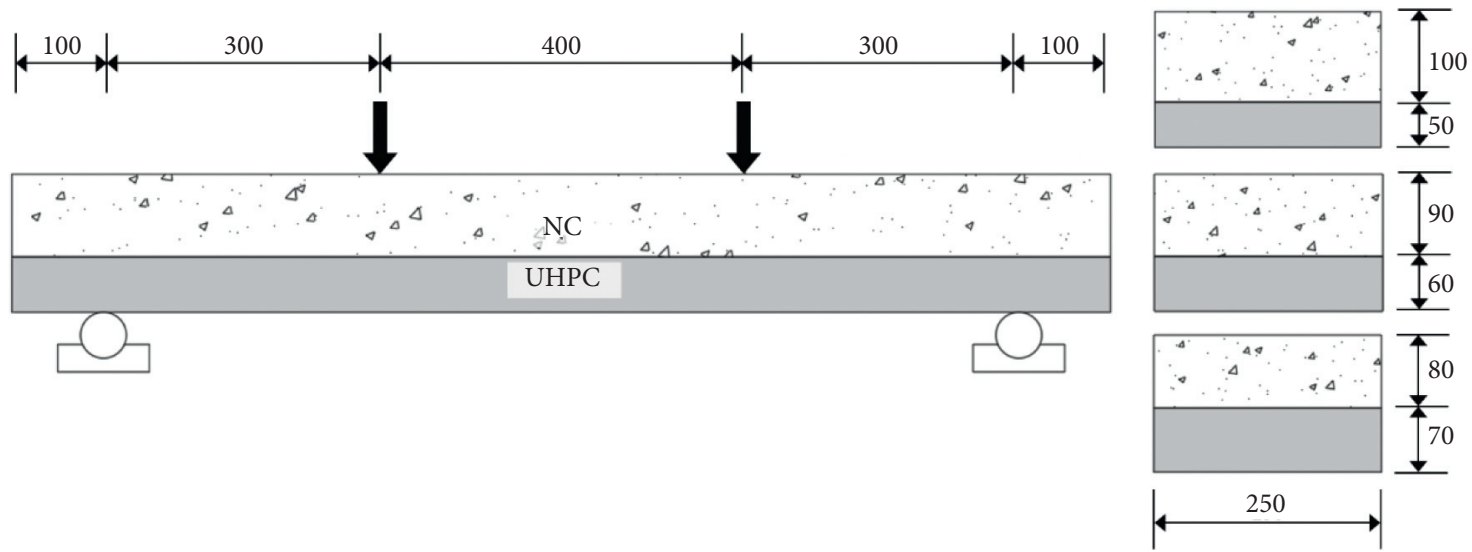

(b)

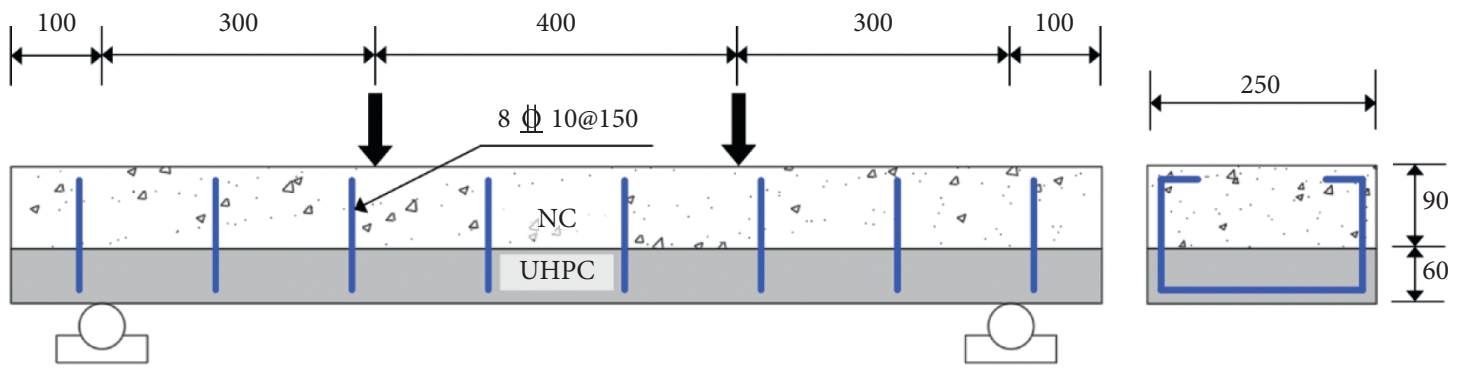

(c)

FIgURe 2: Illustrations of the tested specimens (unit: mm). (a) Specimen U60-LS. (b) Specimens U50, U60, and U70. (c) Specimen U60-S.

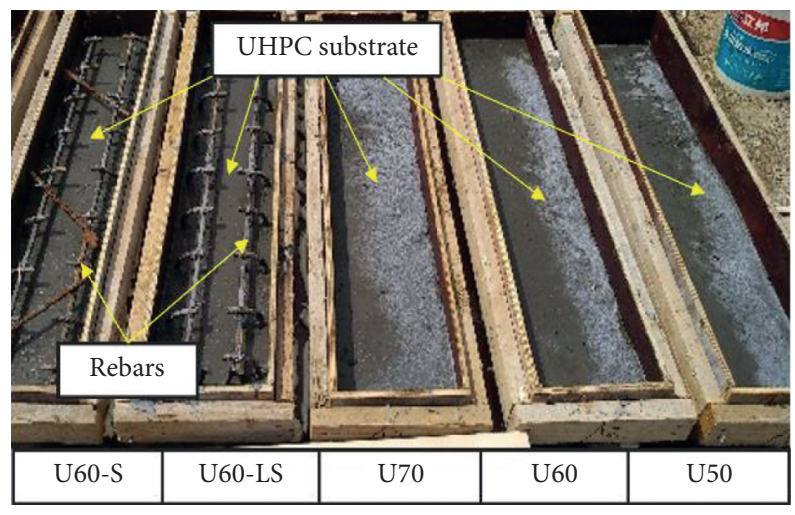

(a)

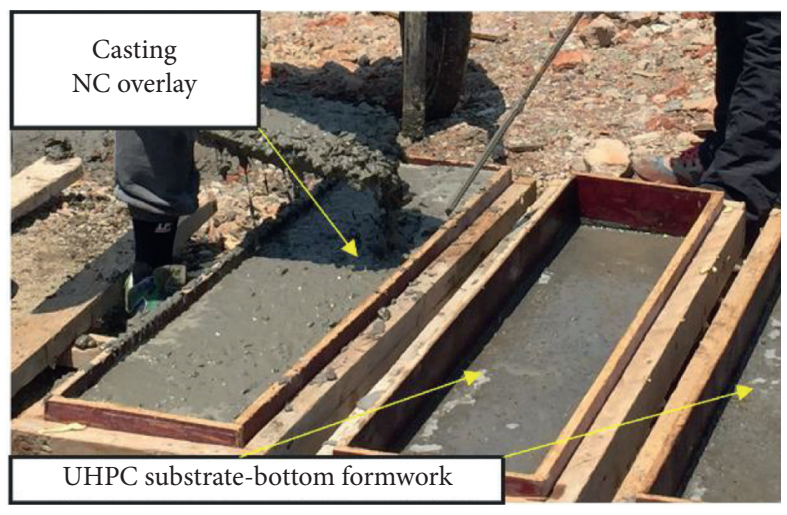

(b)

Figure 3: Construction of NC-UHPC composite decks. (a) UHPC substrate. (b) NC overlay. 
Table 2: Proportions of UHPC mixtures (unit: $\mathrm{kg} / \mathrm{m}^{3}$ ).

\begin{tabular}{lcccc}
\hline Proportion & UHPC power & Steel fiber & Superplasticizer & Water \\
\hline Mixture & 2095 & 156 & 22.10 & 182.4 \\
\hline
\end{tabular}

Note. The mixtures were provided by Sobute New Materials Co., Ltd. (Jiangsu, China).

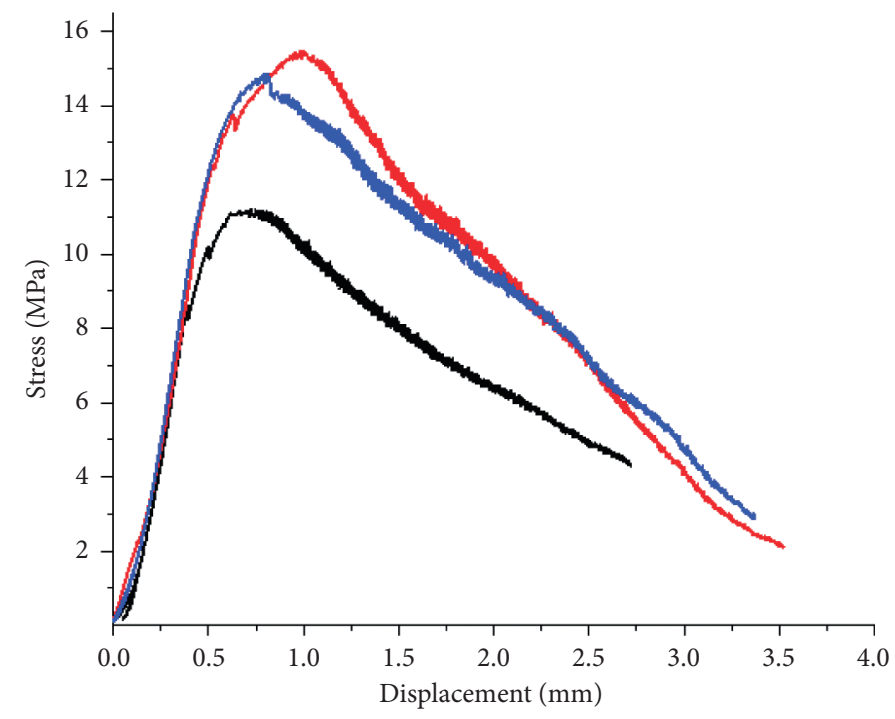

- Sample 1

- Sample 2

- Sample 3

FIgURE 4: Flexural strength test of UHPC.

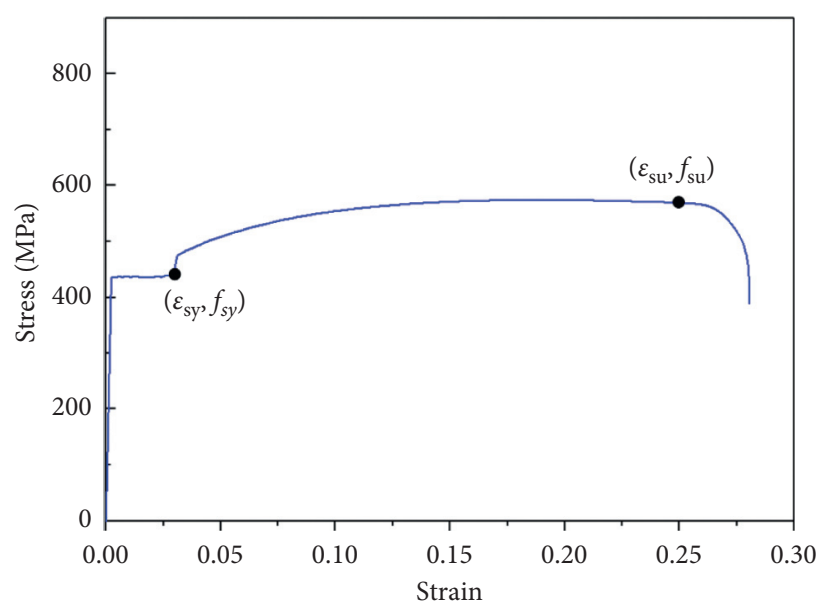

FIGURE 5: Stress-strain relationship of HRB400 rebars.

TABLE 3: Tensile testing of HRB400 rebars.

\begin{tabular}{lcccc}
\hline Rebar & $E_{s}(\mathrm{GPa})$ & $f_{s y}(\mathrm{MPa})$ & $f_{s u}(\mathrm{MPa})$ & 574 \\
\hline \multirow{3}{*}{ HRB400 } & 196 & 435 & $\varepsilon_{s u}(\%)$ \\
& 187 & 436 & 581 & 29.0 \\
& 191 & 426 & 575 & 28.5 \\
\hline
\end{tabular}

4.1. Decks with Longitudinal and Transverse Rebars. Flexural failure mode is the typical failure mode for normal reinforced concrete beam under four-point loading.
Specimen U60-LS was tested to illustrate the effects of the UHPC substrate on the normally reinforced bridge deck. With the substitution of $60 \mathrm{~mm}$ thick UHPC substrate, the 


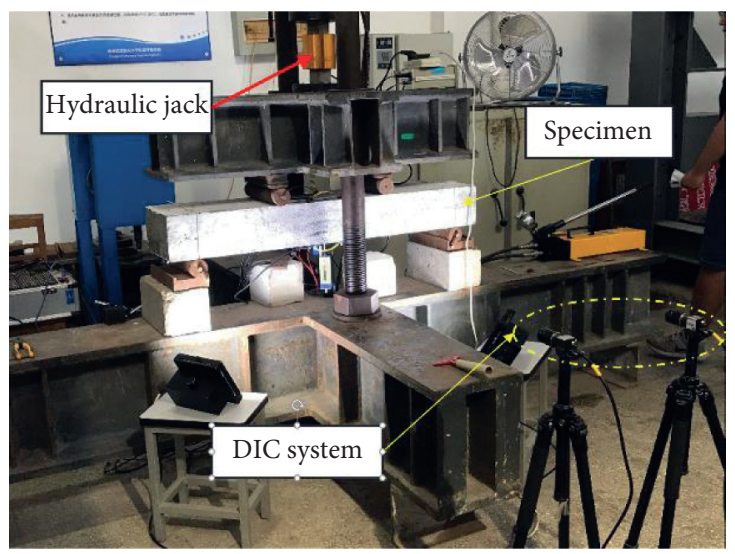

(a)

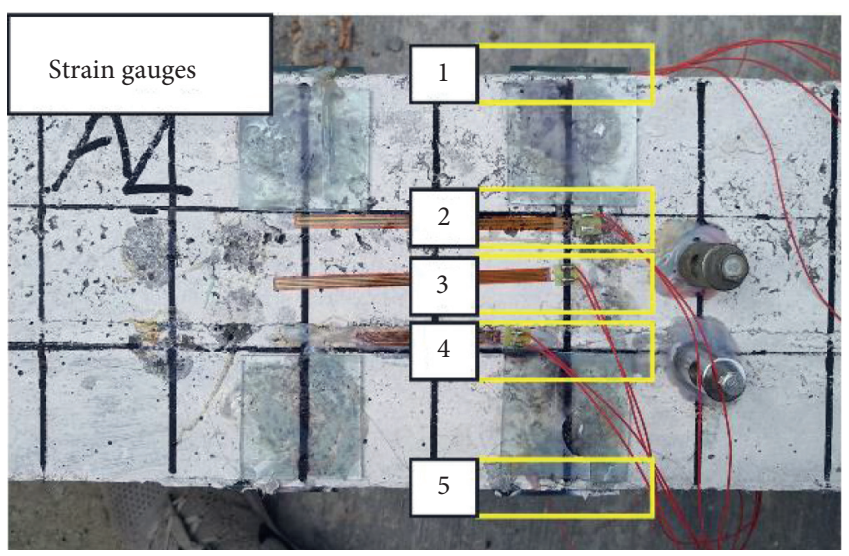

(b)

Figure 6: Experimental setup. (a) Four-point loading. (b) Strain gauges.

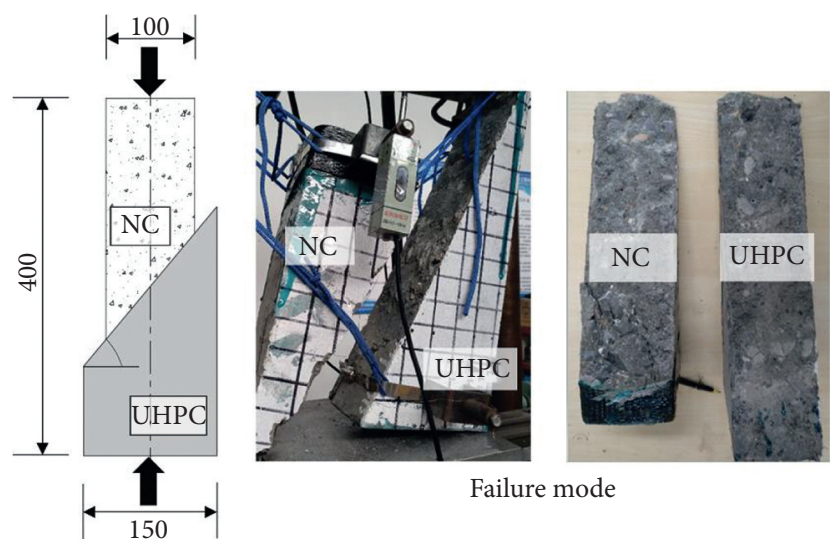

Figure 7: Geometry of interface specimens (mm).

TABLE 4: Slant shear strength results.

\begin{tabular}{lccccc}
\hline Angle & $\begin{array}{c}\text { Sample } \\
\text { no. }\end{array}$ & $\begin{array}{c}\text { Peak load } \\
(\mathrm{kN})\end{array}$ & $\begin{array}{c}\text { Shear stress } \\
(\mathrm{MPa})\end{array}$ & $\begin{array}{c}\text { Fitted stress } \\
(\mathrm{MPa})\end{array}$ & Ratio \\
\hline \multirow{3}{*}{$70^{\circ}$} & 1 & 351.1 & 9.93 & 8.72 & 1.14 \\
& 2 & 416.8 & 12.16 & 9.99 & 1.22 \\
& 3 & 243.2 & 6.78 & 6.64 & 1.02 \\
\hline \multirow{3}{*}{$60^{\circ}$} & 1 & 29.82 & 1.30 & 2.72 & 0.48 \\
& 2 & 488.7 & 14.09 & 14.65 & 0.96 \\
& 3 & 463.5 & 13.36 & 13.99 & 0.95 \\
\hline \multirow{3}{*}{$50^{\circ}$} & 1 & 109.9 & 4.67 & 5.20 & 0.90 \\
& 2 & 556.7 & 18.27 & 18.40 & 0.99 \\
& 3 & 492.3 & 16.16 & 16.49 & 0.98 \\
\hline
\end{tabular}

loading of specimen U60-LS was terminated due to the excessive concrete crushing under the loading point at the peak strength $164 \mathrm{kN}$, rather than the normal flexural failure (see the experiment photo in Figure 9(a)).

DIC technique clearly depicted damage evolutions of specimen U60-LS (see Figure 9(b)). Flexural cracks were first observed in the UHPC substrate, and some cracks already propagated into the $\mathrm{NC}$ overlay at the loading of $76.8 \mathrm{kN}$. Slight concrete crushing was witnessed under the steel roller

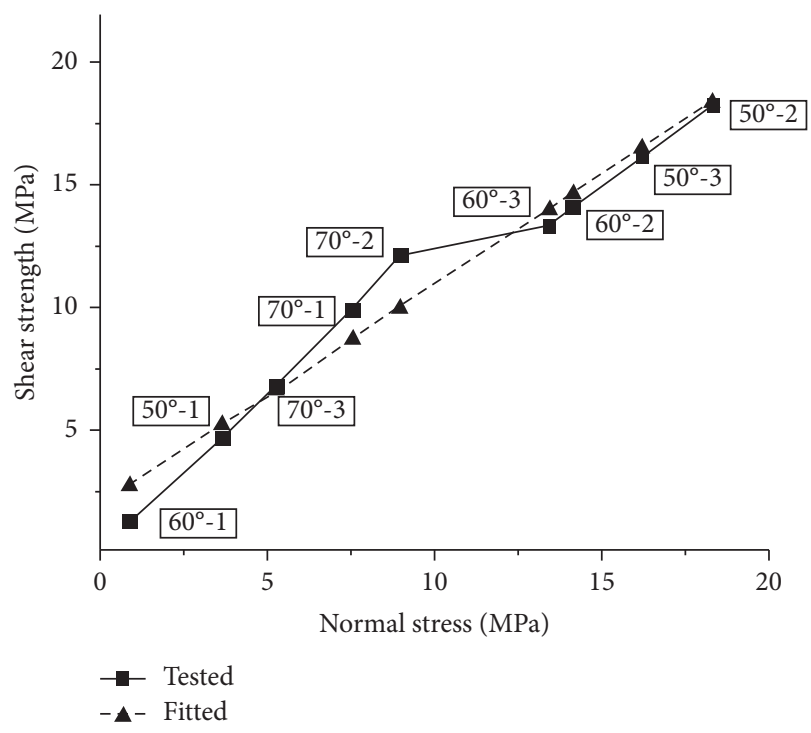

FIGURE 8: Fitting result for the interface shear strength.

at the loading of $116.1 \mathrm{kN}$, accompanied with the crack that extended from the roller to the NC-UHPC interface. Concrete crushing became apparent at loading of about 

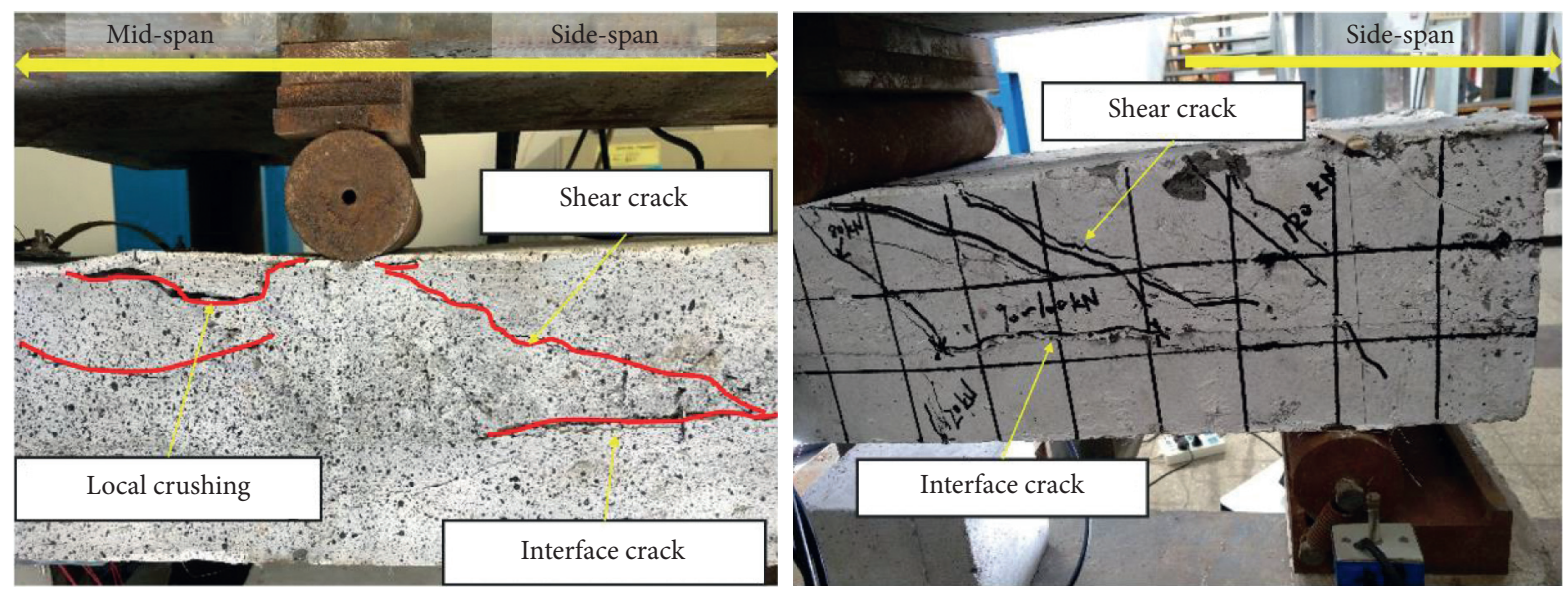

(a)
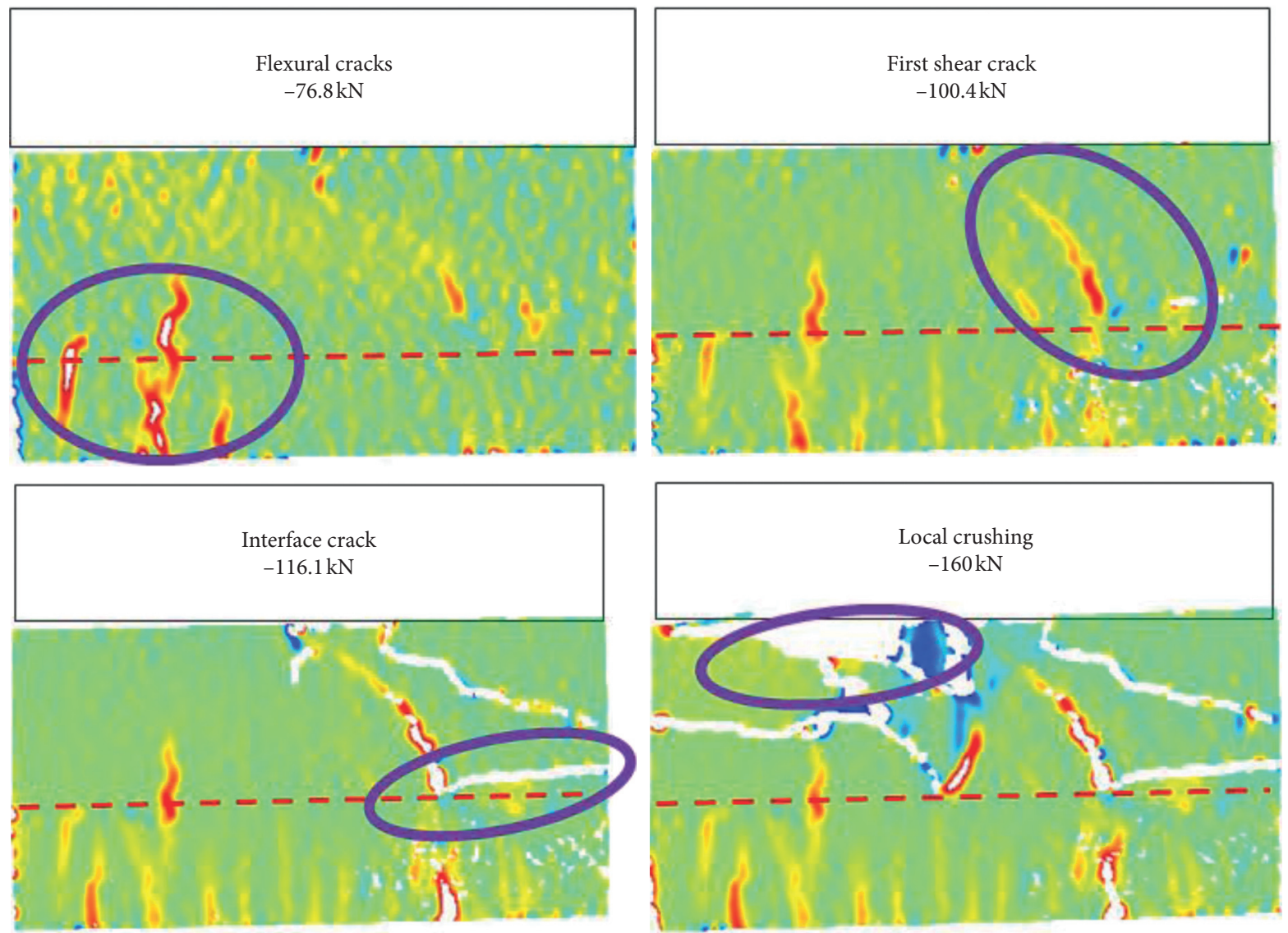

(b)

FIGURE 9: Failure patterns and damage evolutions of specimen U60-LS. (a) Photos for failure pattern. (b) Damage tracking with DIC system.

$160 \mathrm{kN}$, while the overall integrity of UHPC substrate remained and only the widening of its flexural cracks was observed.

The relationships between the total external loading magnitude and the midspan deflection of specimens U60-LS are shown in Figure 10. The force-control loading scheme prevented the post-peak curves. Specimen U60-LS had the peak strength of $164 \mathrm{kN}$. In addition, the specimen U60-LS cracked and failed at $1.89 \mathrm{~mm}$ and $7.88 \mathrm{~mm}$, respectively.
Clearly, the agreed post-peak behaviors of UHPC substrate enhanced the composite deck's strength and ductility capacities.

4.2. Composite Decks without Any Rebars. For the NCUHPC composite decks without any rebars, namely, U50, U60, and U70, various failure patterns and loading capacities were observed. Of special attention was that all the three 


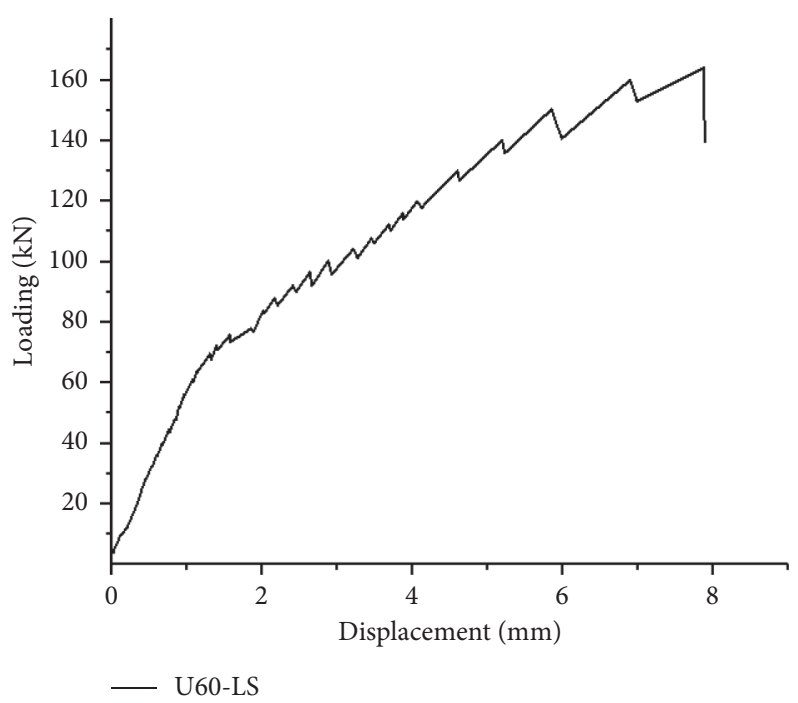

FIgURE 10: Tested load-displacement curve of the midspan for U60-LS.

specimens witnessed the failures with limited ductility, at the initiation of the cracking. The phenomenon contradicted with our postulation that the UHPC layer was able to raise the specimens' ductility to some extent.

Specimen U50 displayed the flexural failure, with a main vertical crack that initiated and propagated between the two loading points, at the peak load of $70.7 \mathrm{kN}$ (see Figure 11(a)). No other visible cracks or the relative displacement at the NC-UHPC interface was noticed. The propagation of the flexural crack was captured, assisted by the DIC system (see Figure 11(b)). The flexural crack initiated with the $0.02 \sim 0.03 \mathrm{~mm}$ width in the UHPC substrate when the external load arrived at $63.8 \mathrm{kN}$. When it increased to $67.0 \mathrm{kN}$, the crack inside the UHPC substrate remained relatively stable, whereas another flexural crack was witnessed in the NC overlay. The two cracks propagated and intertwined when subject to the external load $68.2 \mathrm{kN}$.

Specimen U60 also exhibited the flexural failure at the peak load of $76.9 \mathrm{kN}$, mainly in the NC overlay (see the photos in Figure 12(a)). Similar to specimen U50, two cracks individually initiated and propagated inside the UHPC substrate and NC overlay. Nevertheless, different from specimen U50 whose flexural crack penetrated the whole NC-UHPC composite cross section, the crack inside the UHPC substrate did not lead to full breakage, but not for the $\mathrm{NC}$ overlay. Moreover, the flexural failure of the NC overlay led to the NC-UHPC interface detachment. The DIC images in Figure 12(b) indicate the occurrence of the flexural crack inside the UHPC substrate, subject to the external load of $72.0 \mathrm{kN}$. Due to the agreed UHPC's post-cracking behavior, this crack remained stable while another flexural crack was witnessed inside the NC overlay, subject to the external load of $74.0 \mathrm{kN}$. It is precisely this crack inside the NC overlay that led to the failure of specimen U60.

With the thickness of UHPC substrate increased to $70 \mathrm{~mm}$, shear failure was observed for specimen U70, rather than flexural failure, at the peak load of $100.5 \mathrm{kN}$ (see Figure 13(a)). The overall integrity of the UHPC substrate remained and no visible cracks were observed. The shear crack inside the NC overlay propagated and subsequently evolved along the NC-UHPC interface and led to the detachment. The DIC images in Figure 13(b) indicate the occurrence of some flexural microcracks inside the UHPC substrate which were not traceable by the naked eye, at the external load of $84.1 \mathrm{kN}$. The enhanced post-cracking behavior of the UHPC rendered these flexural cracks stable, even at the termination of the test. The shear crack inside the $\mathrm{NC}$ overlay was observed at the external loading of $91.5 \mathrm{kN}$. Simultaneously, the NC-UHPC bond zone seemed to be not affected and no interfacial cracks were witnessed. When it increased to $100 \mathrm{kN}$, the interface began to crack due to the propagation of the NC's shear crack.

The vertical load-displacement relationships for specimens U50, U60, and U70 are presented in Figure 13. The peak load was $70.7 \mathrm{kN}$ for specimen U50, $73.8 \mathrm{kN}$ for specimen U6.0, and $100.5 \mathrm{kN}$ for specimen U70. Intuitively, the $60 \mathrm{~mm}$ and $70 \mathrm{~mm}$ thick substrates gained $4.4 \%$ and $42.1 \%$ increments in the peak load-carry capacity, compared to specimen U50. Also, the elastic stiffness was affected by the thickness of the UHPC substrate, which was 61.8 for specimen U50, 65.2 for specimen U60, and 79.5 for specimen U70.

Discernable performances in terms of ductility were witnessed for the composite decks without any rebars, although all exhibited limited overall ductility (see Figure 14). The best specimen which showed an apparent plateau was specimen U50, whose UHPC substrate fully broke at the termination of the test. Comparatively, specimens U60 and U70 had the ignorable plateau, which was attributed to their failure modes: the flexural crack (U60) and the brittle shear crack (U70) of the brittle NC overlay. 


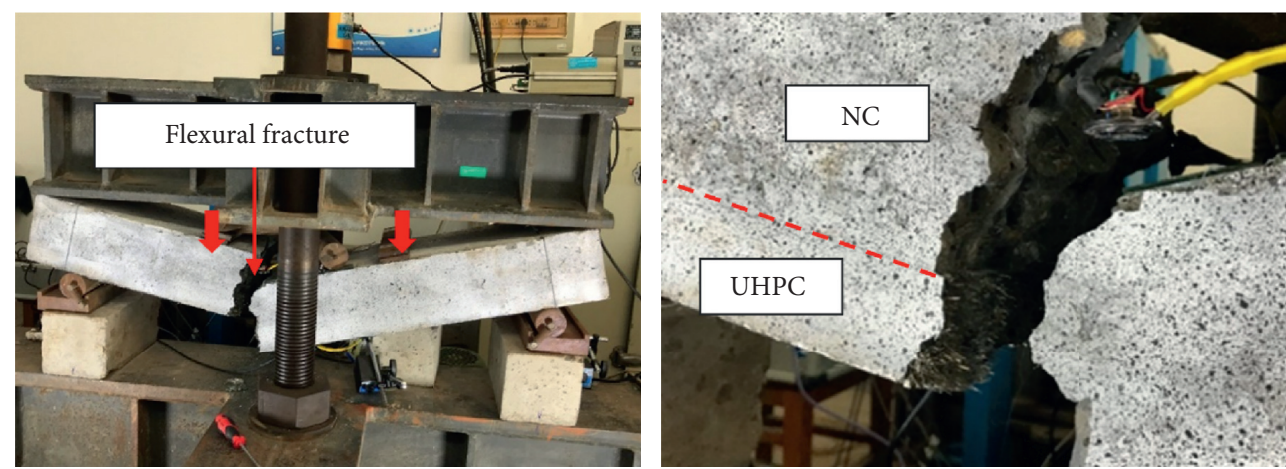

(a)

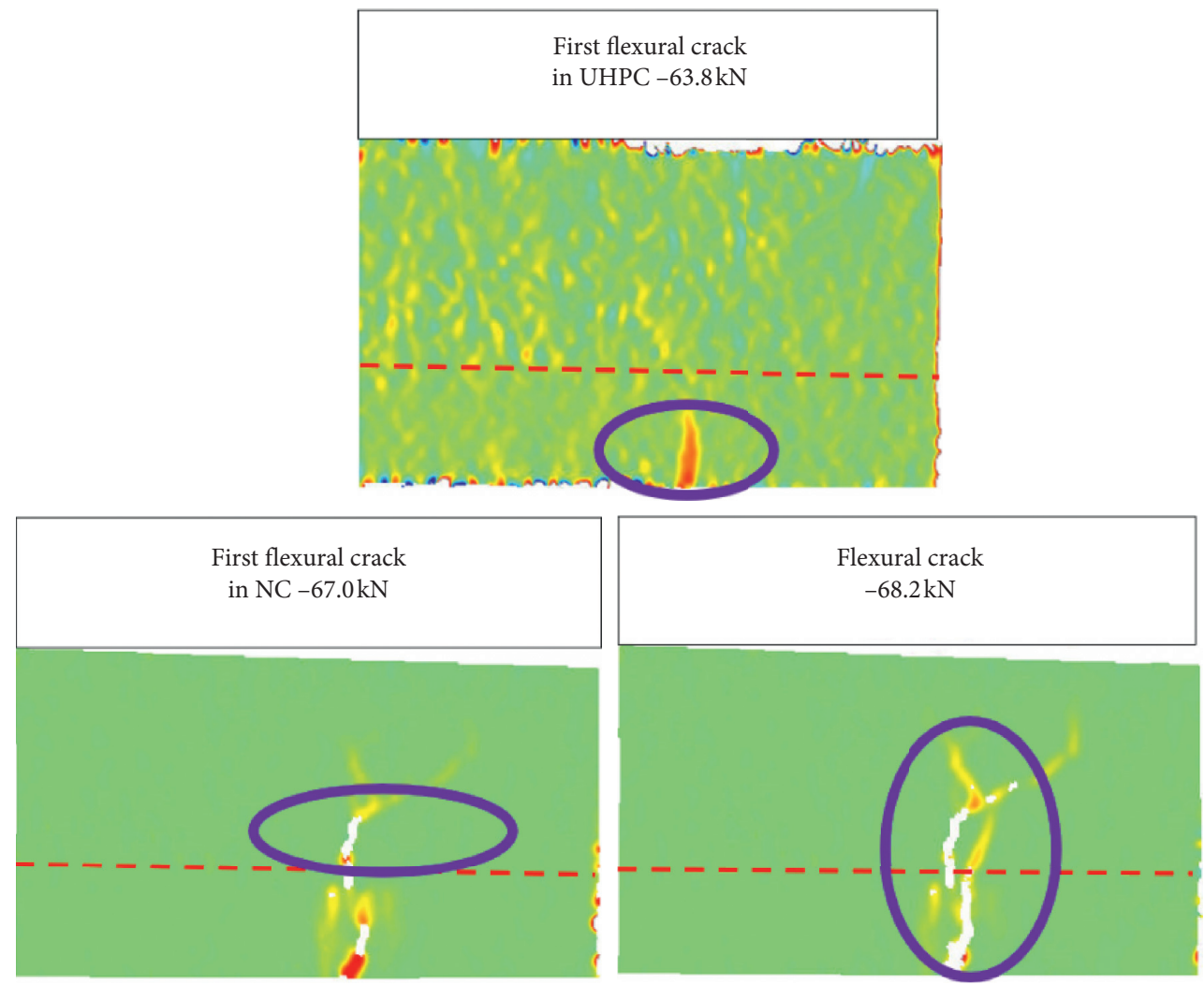

(b)

FIgURE 11: Failure patterns and damage evolutions of specimen U50. (a) Photos for failure pattern. (b) Damage tracking with DIC system.
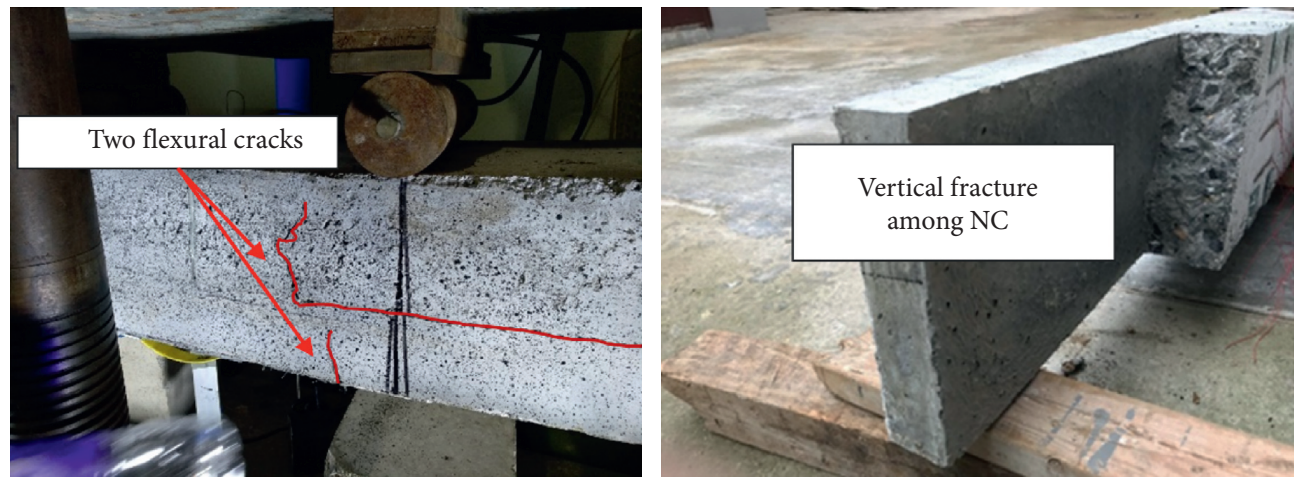

(a)

Figure 12: Continued. 


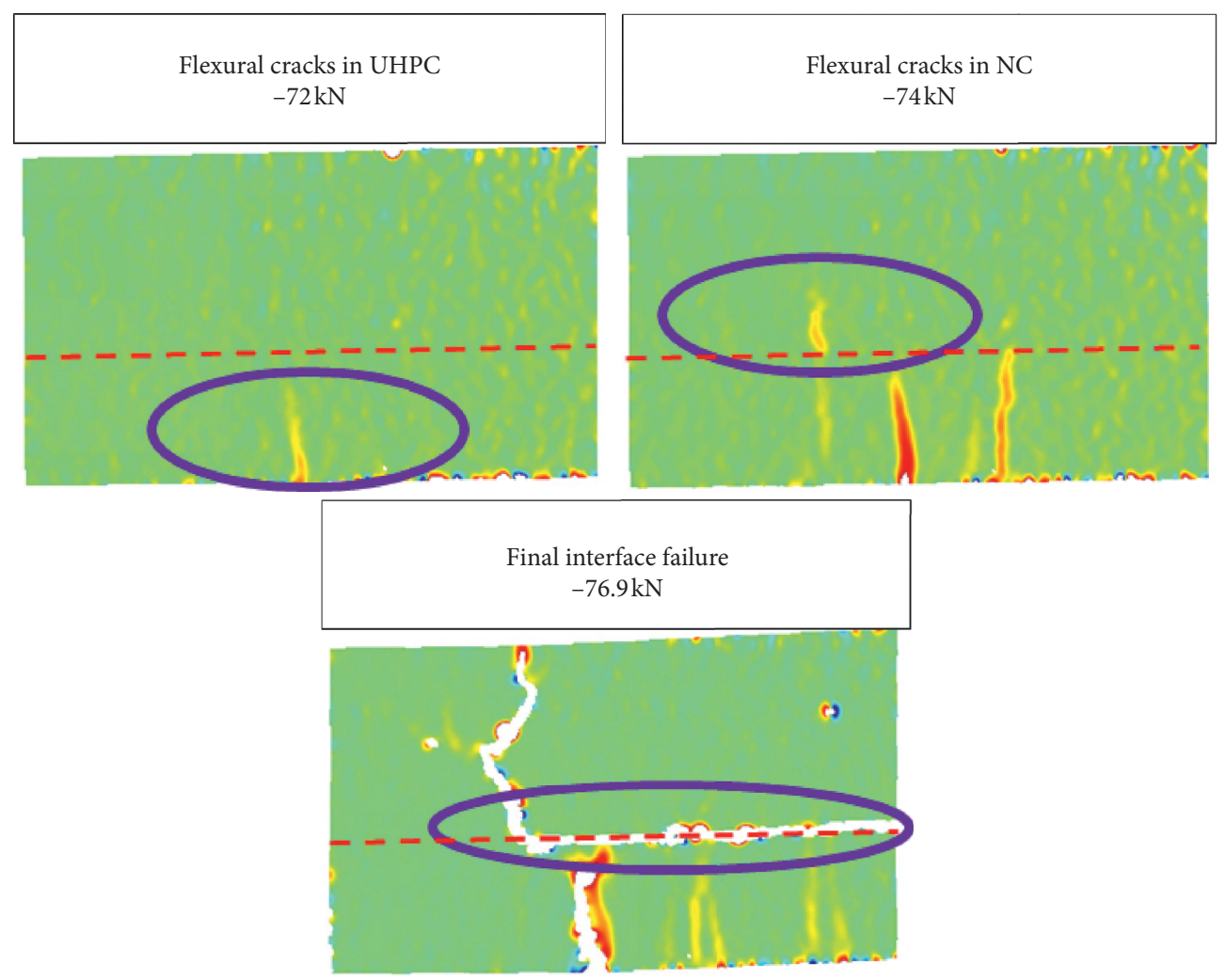

(b)

Figure 12: Failure patterns and damage evolutions of specimen U60. (a) Photos for failure pattern. (b) Damage tracking with DIC system.
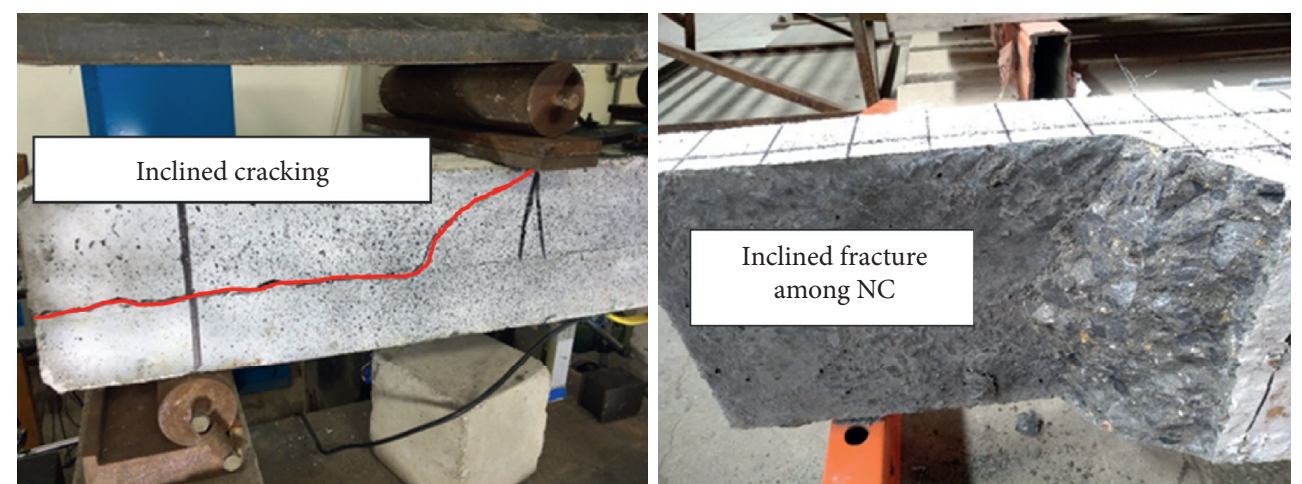

(a)

Figure 13: Continued. 


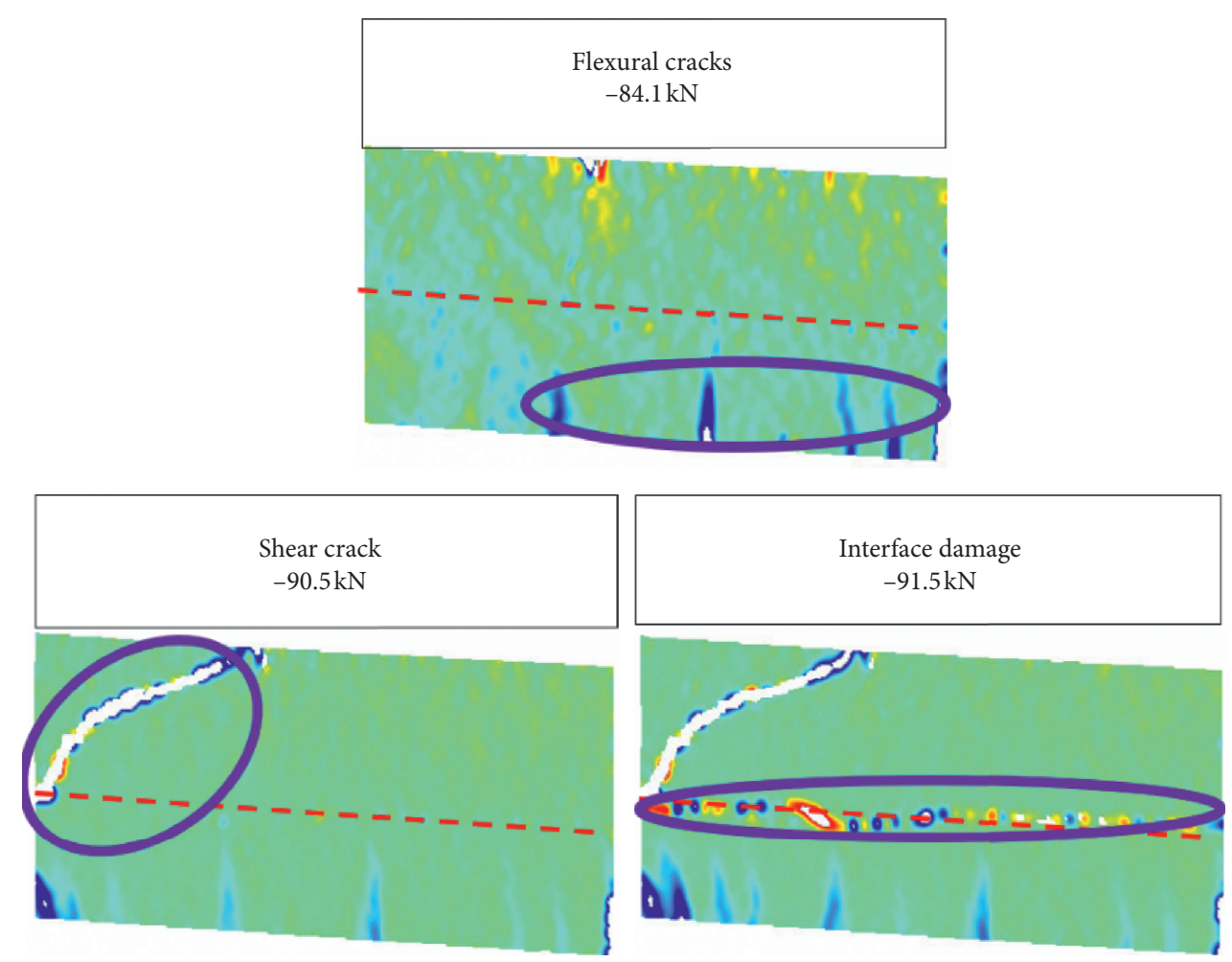

(b)

FIGURE 13: Failure patterns and damage evolutions of specimen U70. (a) Photos for failure pattern. (b) Damage tracking with DIC system.

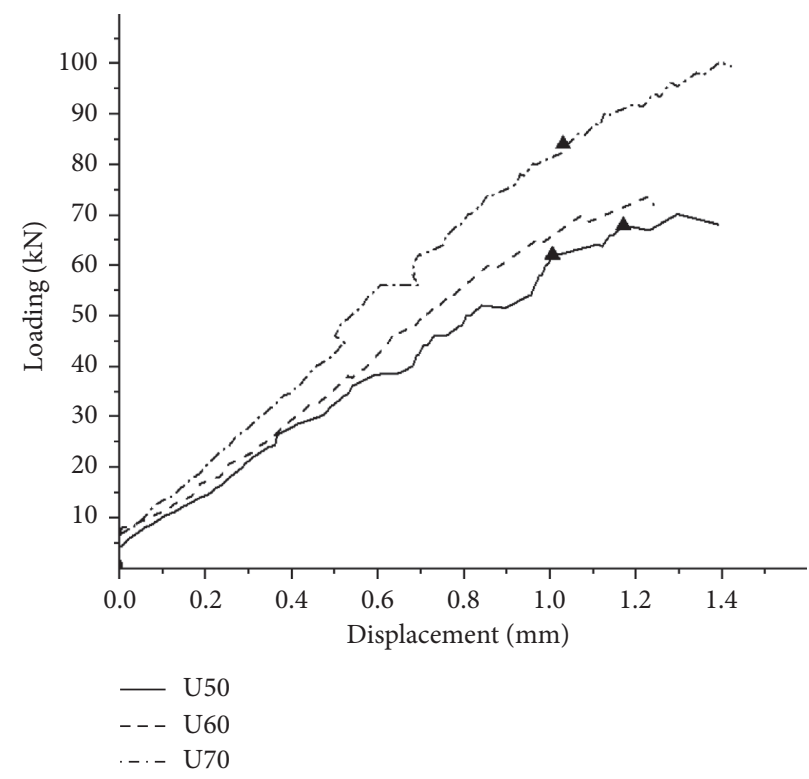

Figure 14: Load-displacement curves of tested beams without reinforcement.

4.3. Composite Decks with Merely Transverse Rebars. The static behaviors of the composite deck with merely transverse rebars (specimen U60-S) are compared with its counterpart without any rebars (specimen U60).

Specimen U-60S displayed the flexural failure at the peak load of $56.2 \mathrm{kN}$, with the crack initiating inside the UHPC substrate and propagating into the NC layer (see
Figure 15(a)). The overall integrity of the NC-UHPC interface remained and no relative displacement was observed. The DIC observation indicated the occurrence of the flexural crack at the bottom of UHPC substrate at the external loading of $47.8 \mathrm{kN}$. With load increased to $54.2 \mathrm{kN}$, another crack was observed inside the NC layer. Finally, the crack inside the UHPC substrate propagated into the NC 

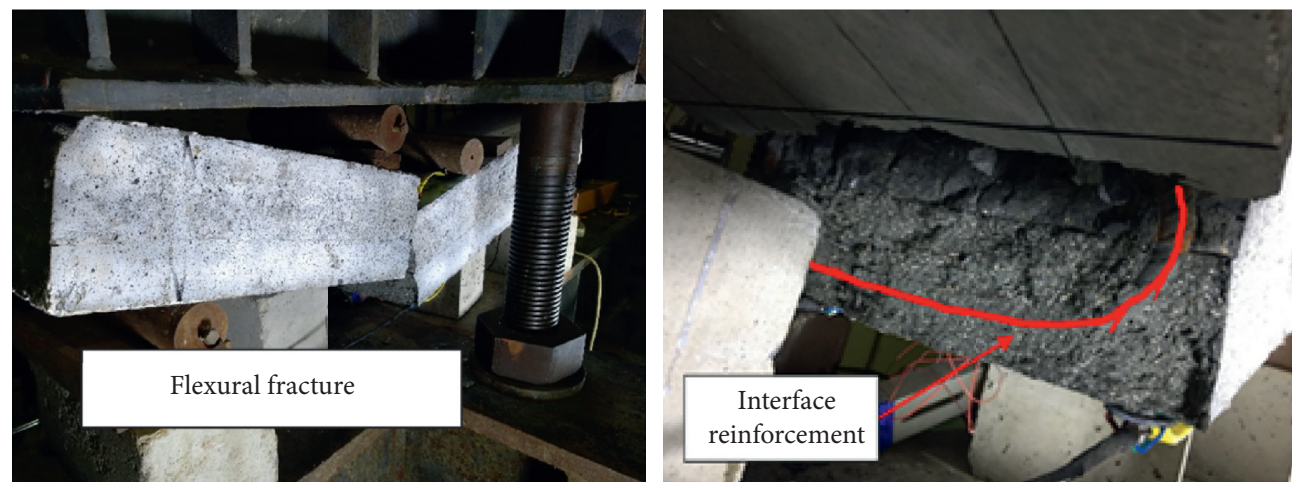

(a)

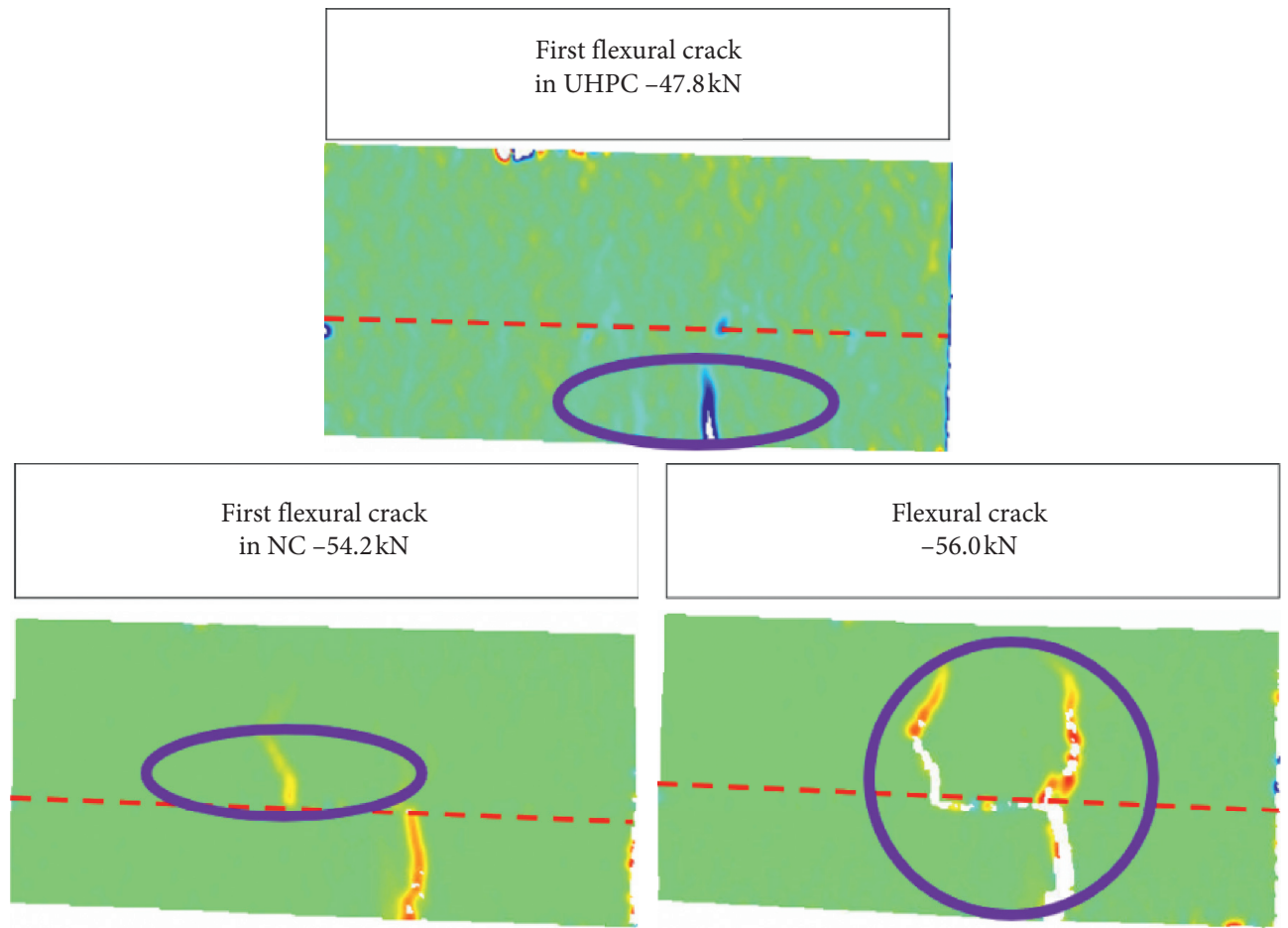

(b)

FIGURE 15: Failure patterns and damage evolutions of specimen U60-S. (a) Photos for failure pattern. (b) Damage tracking with DIC system.

layer and led to the brittle failure at the peak load of $56.2 \mathrm{kN}$.

Compared to specimen U60, the peak load shrank from $70.7 \mathrm{kN}$ to $56.2 \mathrm{kN}$, nearly $20.5 \%$ drop. The transverse rebars negatively affected the composite decks without longitudinal rebars. The reason was largely attributed to the weakening of the cross section with the introduction of the transverse rebars. Figure 15(b) clearly demonstrates the fracture surface, which was exactly located at the position of one transverse rebar.

The comparison of specimens U60 and U60-S, in terms of vertical load-displacement relationship, is plotted in Figure 16. Interestingly, although with lowered flexural strength, the specimens exhibited the most ductile behaviors. The reason lies in their failure modes. The crack in the NC overlay led to the failure of specimen U60 (see Figure 12(a)), whereas the UHPC substrate's breakage resulted in the failure of specimen U60-S (see Figure 14). The more ductile behavior of the UHPC over the NC contributed to the specimen U60-S' enhanced ductility.

\section{Carrying Capacity of NC-UHPC Composite Decks}

The test results clearly demonstrated that the increasing thickness of UHPC substrate altered the flexural failure of specimen U50 to the shear failure of specimen U70. Consequently, the analytical methods to derive the flexural and shear strengths of the conventional NC decks should be modified for composite NC-UHPC beams. The context of a composite deck's carrying capacity embraces the flexural and the shear strengths, respectively. The lower value would govern the composite deck's failure mode. Analytical predictions for predicting the carrying capacity are derived. 


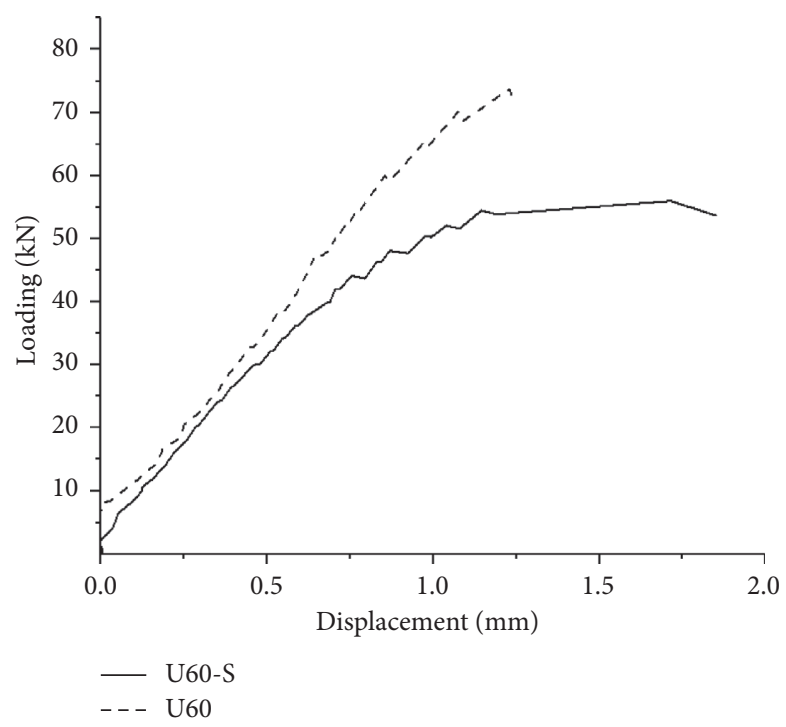

FIgURE 16: Tested load-displacement curve of the midspan for U60-S.

5.1. Flexural Strength. A main concern about predicting the flexural strength of a composite NC-UHPC beam is whether the plane section assumption is still valid. Having benefited from the arranged strain gauges (see Figure 6), the evolutions of compressive or tensile strains with the external loading are summarized in Figure 17, for specimens U50, U60, U70, and U60-LS. Clearly, the plane assumption was valid, especially within the elastic period. After the initial cracking, the tensile strains deviated slightly from the predicted strains from the plane assumption. Hence, it is still necessary to conduct certain research on the elastic ultimate flexural crack loading of this NC-UHPC composite beam to predict its behaviors.

For the analytical expression for predicting flexural strength of a reinforced composite deck, i.e., specimen U60LS, please refer to Guo [22]. Here, we focus on the cracking and flexural strengths of a composite deck without longitudinal or flexural rebars. Plane assumption is still adopted and it yields the strain and stress distributions illustrated in Figure 18.

The force balance and the moment balance of the cross section require

$$
\begin{gathered}
\int_{-\bar{y}}^{-\bar{y}+h_{1}} \sigma_{1} \cdot b \cdot \mathrm{d} y+\int_{-\bar{y}+h_{1}}^{h-\bar{y}} \sigma_{2} \cdot b \cdot \mathrm{d} A=0, \\
M=\int_{-\bar{y}}^{-\bar{y}+h_{1}} \sigma_{1} y \mathrm{~d} A+\int_{-\bar{y}+h_{1}}^{h-\bar{y}} \sigma_{2} y \mathrm{~d} A,
\end{gathered}
$$

where $\sigma_{1}$ and $\sigma_{2}$ are the stress in the tensile and compressive zone, respectively; $b$ is the width of the deck; and $\bar{y}$ is the distance between the neutral axis and the bottom deck. For a rectangular deck, the position of the neutral axis can be obtained as follows:

$$
\bar{y}=\frac{\left(E_{1}-E_{2}\right) h_{1}^{2}+E_{2} h^{2}}{2\left[E_{1} h_{1}+E_{2}\left(h-h_{1}\right)\right]},
$$

where $E_{1}$ and $E_{2}$ are Young's modulus of UHPC and NC, respectively, and $h_{1}$ and $h_{2}$ are the height of UHPC and NC layers, respectively. The corresponding loading $P_{f}$ applied on the NC-UHPC composite beam with the ultimate flexural moment $M_{u}$ is

$$
P_{f}=2 \frac{M_{u}}{l}
$$

Crack and flexural strengths of a composite NC-UHPC deck rely on the constitutive model of UHPC. Based on the text in Section 2, the tensile stress-strain relationship of UHPC is simplified as shown in Figure 19 [23, 24]. Cracking strength of a composite NC-UHPC deck is determined when the tensile stress of the outmost UHPC fiber arrives at its peak strength (see Figure 19). Similarly, a composite deck's flexural strength is obtained when the tensile strain of the outmost UHPC fiber arrives at its ultimate value (see Figure 20) The predicted tensile strengths for specimens U50, U60, and U70 are compared with the experimental values in Table 5.

5.2. Shear Strength. The failure pattern of specimen U70 indicated the two stages of damage evolutions (see Figure 13). Initially, the shear cracks occurred in the NC overlay. Subsequently, the propagation of the shear crack triggered the detachment of the NC and UHPC parts and rendered the NC part a free body.

Enlightened from the aforementioned damage process, we assert that the NC-UHPC interface failure governs the shear strength of a composite deck without the transverse rebars crossing the interface (see Figure 21). By assuming that the angle between the shear crack and the interface is 45 [25], the limit shear strength of a composite deck can be derived as

$$
P_{v}=2 \frac{\tau_{u} I_{z} b}{S_{z}} \cdot \frac{l_{p}}{l_{\text {crit }}},
$$




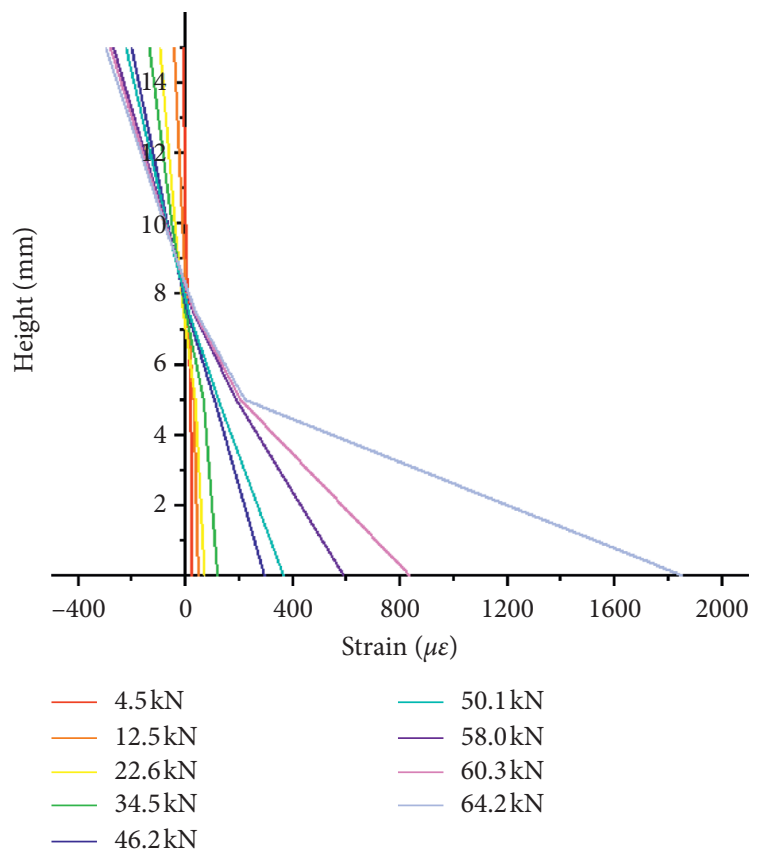

(a)

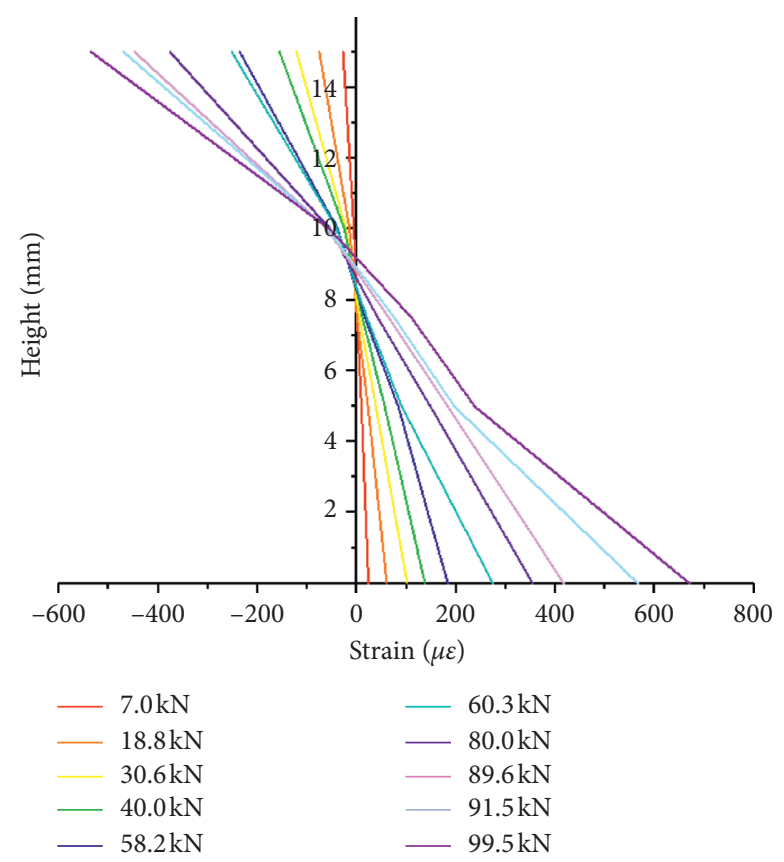

(c)

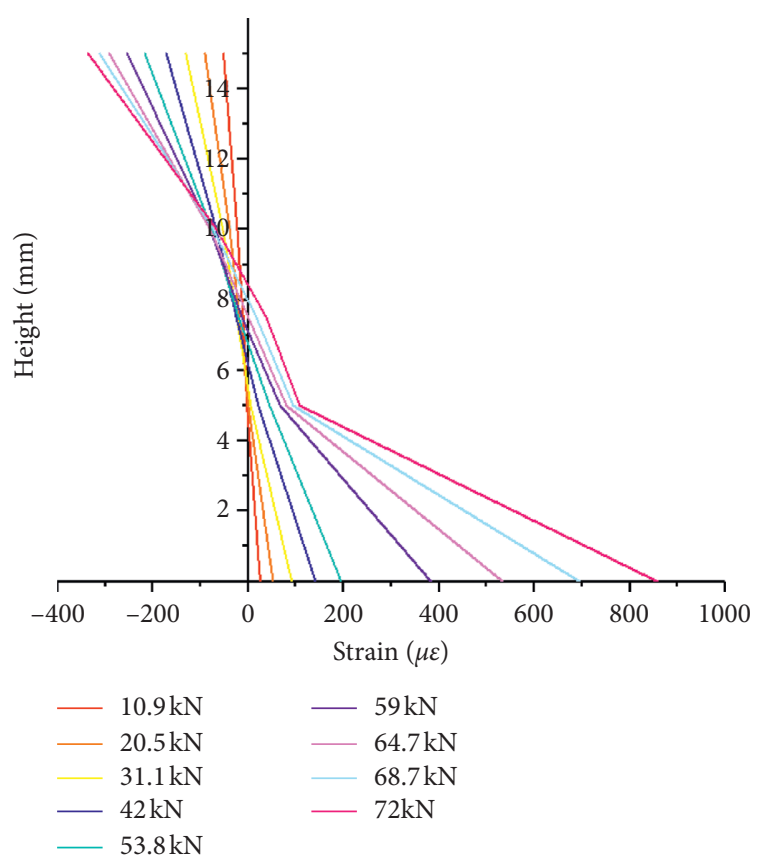

(b)

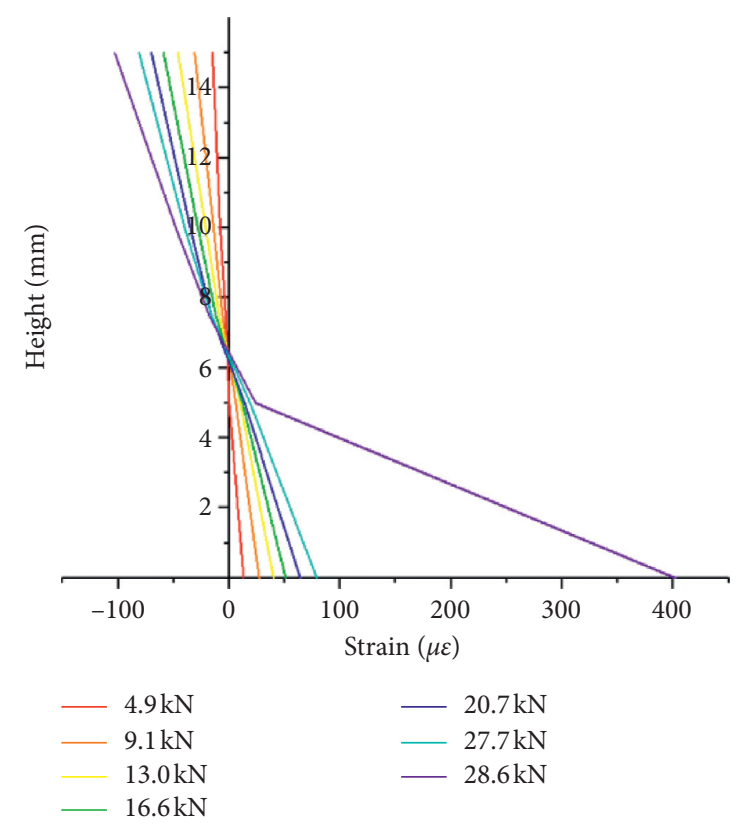

(d)

FIGURE 17: Strain distributions for tested composite decks. (a) Specimen U50. (b) Specimen U60. (c) Specimen U70. (d) Specimen U60-LS.

where $\tau$ is the shear strength of the interface between NC and UHPC; $P_{v}$ is the corresponding loading applied on the NC-UHPC composite beam at the shear failure; $S_{z}$ is the static moment of the area above the neutral axis; and $I_{z}$ is the principal inertia moment of the section. The UEP is used to determine the critical length $l_{\text {crit }}$ and the loading length $l_{p}$.

Moreover, the predicted shear strengths for specimens U50, U60, and U70 are compared with the experimental values in Table 6.

\section{Numerical Simulation considering Interface Behaviors}

The aforementioned test provides valuable static behaviors of the NC-UHPC composite decks from the experimental aspects. Nevertheless, constructing a reliable 3D FE model is vital to probe meaningful insights of the composite decks, from the numerical aspects. The primary goal of the FE study is to gain a deeper understanding of the local and global behaviors of the composite decks, either with or without rebars. 

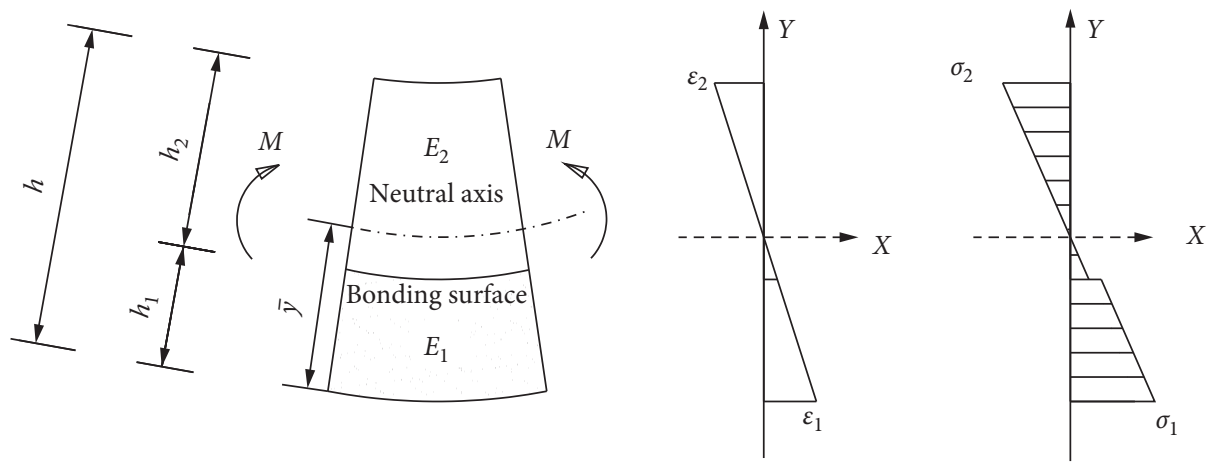

FIGURE 18: Calculation segment diagram among the pure bending zone.

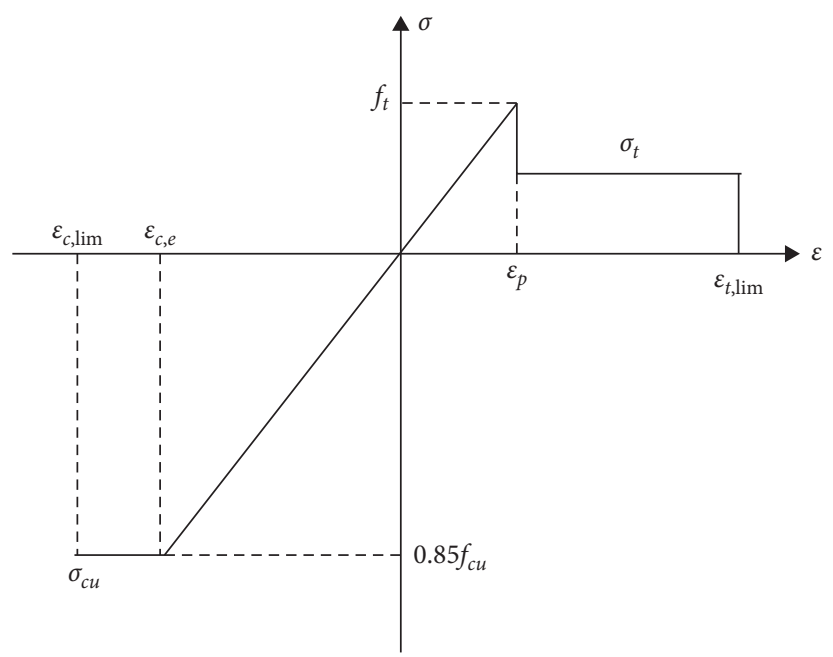

FIgure 19: Constitutive relation of UHPC.

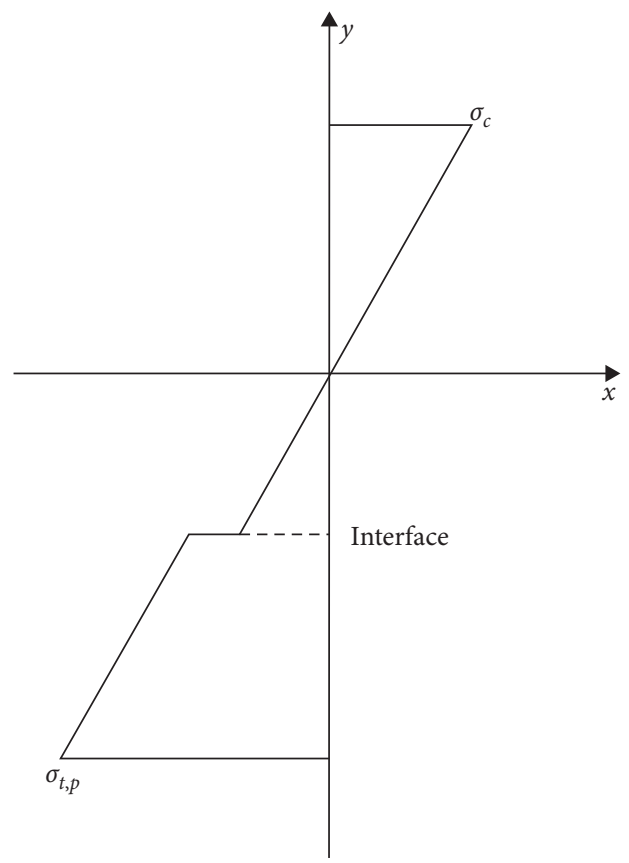

(a)

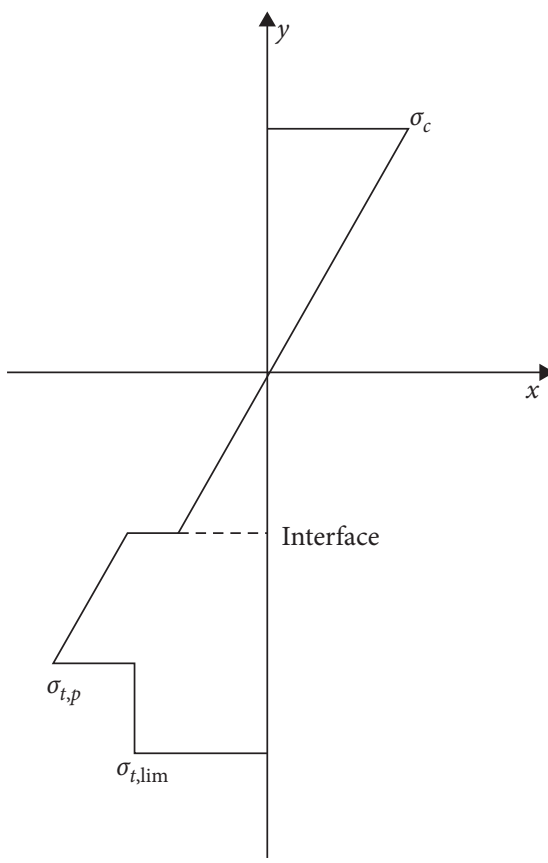

(b)

Figure 20: Stress distribution for the flexural section. (a) Stress distribution for cracking loading. (b) Stress distribution for ultimate loading. 
TABle 5: Predicted results for tested composite beams.

\begin{tabular}{|c|c|c|c|c|c|}
\hline & & U60-LS & U50 & U60 & U70 \\
\hline \multirow{2}{*}{ Cracking strength $(\mathrm{kN})$} & Test & 76.8 & 66.8 & 70.2 & 84.5 \\
\hline & Calculation & 86.57 & 79.83 & 80.54 & 80.83 \\
\hline \multirow{2}{*}{ Ultimate strength $(\mathrm{kN})$} & Test & 164 & 71.8 & 76.9 & 103.6 \\
\hline & Calculation & 214.71 & 96.73 & 97.27 & 97.51 \\
\hline Failure pattern & & Local crushing & Flexural & Flexural & Shear \\
\hline
\end{tabular}

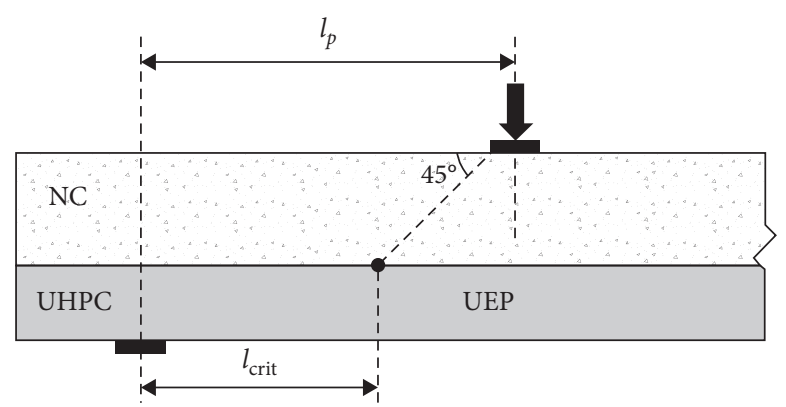

FIGURE 21: Location of ultimate evaluation point for Texas girders.

Table 6: Predicted results for tested composite beams.

\begin{tabular}{|c|c|c|c|c|c|}
\hline & & U60-LS & U50 & U60 & U70 \\
\hline \multirow{2}{*}{ Ultimate strength $(\mathrm{kN})$} & Test & - & - & - & 103.6 \\
\hline & Calculation & - & - & - & 102.9 \\
\hline Failure pattern & & Local crushing & Flexural & Flexural & Shear \\
\hline
\end{tabular}

The model is implemented using the commercial software ATENA [26]. ATENA is focused on reinforced concrete structures and is widely used for both design and research. Its material library contains a variety of advanced constitutive models, which are capable of capturing concrete behaviors under bi- and triaxial loading, nonlinear performance of interface, and concrete cracking.

6.1. Geometric Models. The 3D FE models for all the composite decks were constructed, except specimen U60-S whose impaired peak load was attributed to the weakening of the cross section, which was hard to be reflected in the numerical models. The geometric model is illustrated in Figure 22, with specimen U60-LS being taken as an illustration. The UHPC substrate and the NC overlay are meshed with $3 \mathrm{D}$ hexahedral elements, while the longitudinal and transverse rebars are modeled with $3 \mathrm{D}$ truss elements. Perfect bond is assumed between the rebars and the UHPC/ NC matrix, which means relative displacement is not allowed in the models.

As indicated in the previous section, the interface properties generated critical effects on the composite decks' overall behaviors. The interface is modeled through "3D interface" modulus in ATENA, where the coefficients $c$ and $\mu$ in equation (2) can be properly defined. It is noted that the values for the two coefficients obtained in the slant shear tests are adopted for the simulations.
6.2. Constitutive Models. A fracture-plastic model is employed to describe the behavior of NC and UHPC materials, consisting of a fracture model based on a smeared crack formulation and crack band concept and a plasticity model residing on a plastic failure surface, intended to accurately capture concrete behavior in tension (fracture) and compression (crushing). In the fracture model, an exponential softening is assumed for concrete after it reaches its tensile strength. For the plasticity model, it follows a hardening/softening failure surface. The equivalent uniaxial stress-strain model for concrete implemented in the ATENA model is shown in Figure 23. In the fracture model, an exponential softening is assumed for concrete after it reaches its tensile strength. The model for concrete contains a number of free material and mechanical parameters, some of which are allowed to vary so as to capture the behaviors of concrete under different types of stress condition. In this study, default values or values based on AASHTO-prescribed formulas are assigned to these parameters. The free parameters in the modeling conducted are shown in Table 7.

When combining these two models, the following important interactions are taken into account:

(1) Tensile strength reduction after concrete crushing, which is captured by adding equivalent plastic strain to tensile damage.

(2) Compressive strength reduction after concrete cracking, which is described using the modified compression field theory [27]. 

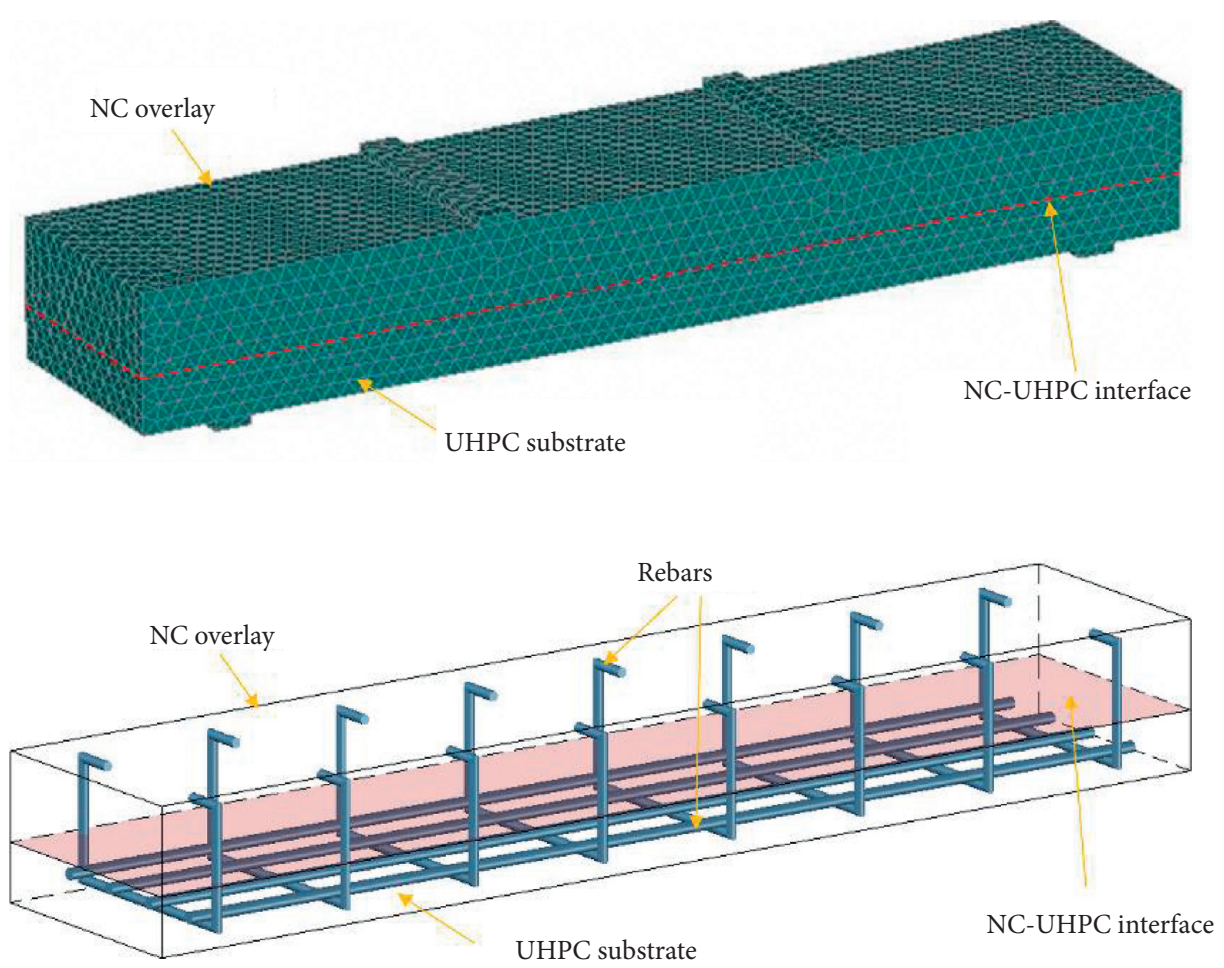

Figure 22: Summary of reinforcing layout and ATENA models for the NC-UHPC slabs.

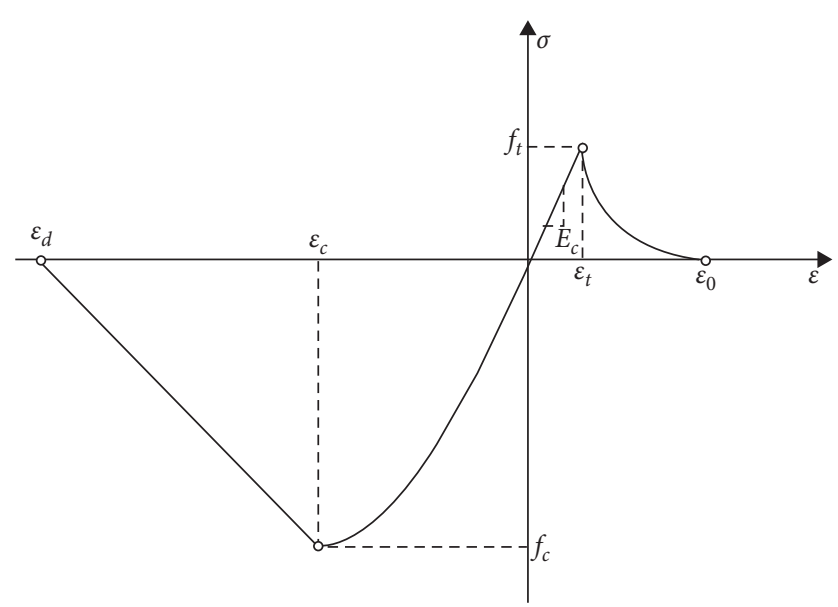

Figure 23: Constitutive model for concrete (ATENA).

(3) Shear strength of cracked concrete, which is calculated based on the modified compression field theory [27].

For longitudinal and transverse rebars, the classical elastic-plastic material model is employed. The stress-strain relation is characterized by the bilinear constitutive law. The initial ascending part of the bilinear law is governed by Young's modulus of steel, and the horizontal plateau is dictated by the yield strength and limit strain. ATENA software can also simulate the interfacial failure and slip which were found in the tested specimens.
6.3. Comparisons of Experimental and Simulation Results. ATENA provides a post-processing interface to graphically illustrate the simulation results. The stress and strain in concrete materials can be graphically demonstrated on the model, as well as the cracks. The comparisons of the experimental and numerical failure modes are illustrated in Figure 23. ATENA permits a threshold level of damage to be illustrated; that is, only cracks with width greater than $0.2 \mathrm{~mm}$ are shown in output graphics.

Generally, the 3D FE models well captured the cracking patterns of composite decks. Numerical simulation of specimen U50 indicates the flexural crack at the midspan, which initiates inside the UHPC substrate and penetrates the whole composite cross section (see Figure 24(a)).

For specimen U60, the simulation results clearly reflect the two separate main cracks, with one located inside the UHPC substrate and the other inside the NC overlay (see Figure 24(b)). The simulation also indicates that the crack inside the NC overlay finally leads to the failure of specimen U60. Moreover, the interface between the UHPC and the NC is broken and the apparent slip is witnessed at the end of the deck, which is marked in Figure 24(b).

There are obvious inclined shear cracks in tested slabs UHPC-70 and UHPC-60LS. The specimen finally experienced the inclined shear fracture in $\mathrm{NC}$ and the horizontal interface failure. The final failure in the tested slab UHPC60LS is observed in the local zone under loading points.

Comparisons of the vertical load-displacement relationships for the composite decks are depicted in Figure 25. The experimental and numerical peak load are $71.8 \mathrm{kN}$ vs 
TABLE 7: Summary of concrete strength properties.

\begin{tabular}{lcc}
\hline & Normal concrete C50 & UHPC \\
\hline Concrete Properties & & \\
Compressive strength & $12.1 \mathrm{ksi}$ & $12.7 \mathrm{ksi}$ \\
Strain at compression strength & $3000 \mu \varepsilon$ & $2800 \mu \varepsilon$ \\
Split tensile strength & $867 \mathrm{psi}$ & $823 \mathrm{psi}$ \\
Modulus of rupture & $991 \mathrm{psi}$ & $1190 \mathrm{psi}$ \\
Deck compressive strength & $4.5 \mathrm{ksi}$ & $9.2 \mathrm{ksi}$ \\
\hline Reinforcing steel properties & & $\# 10$ \\
Bar size & $70.0 \mathrm{ksi}$ & $64.7 \mathrm{ksi}$ \\
Yield strength & $109.0 \mathrm{ksi}$ & $102.0 \mathrm{ksi}$ \\
Ultimate strength
\end{tabular}
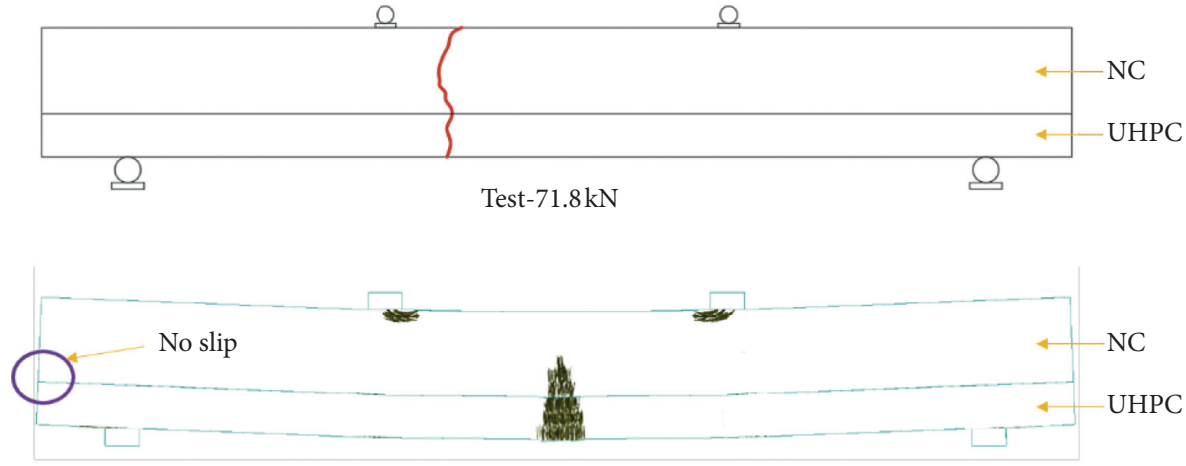

Simulation-70.6kN

(a)

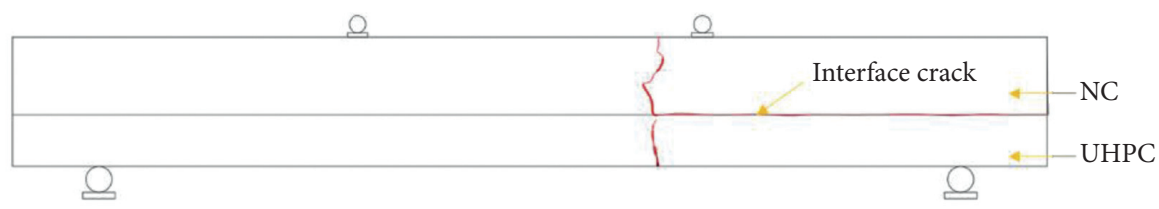

Test-76.9kN

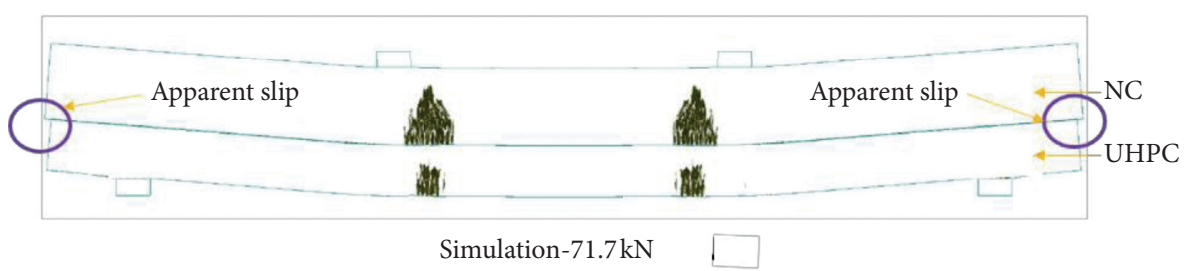

(b)
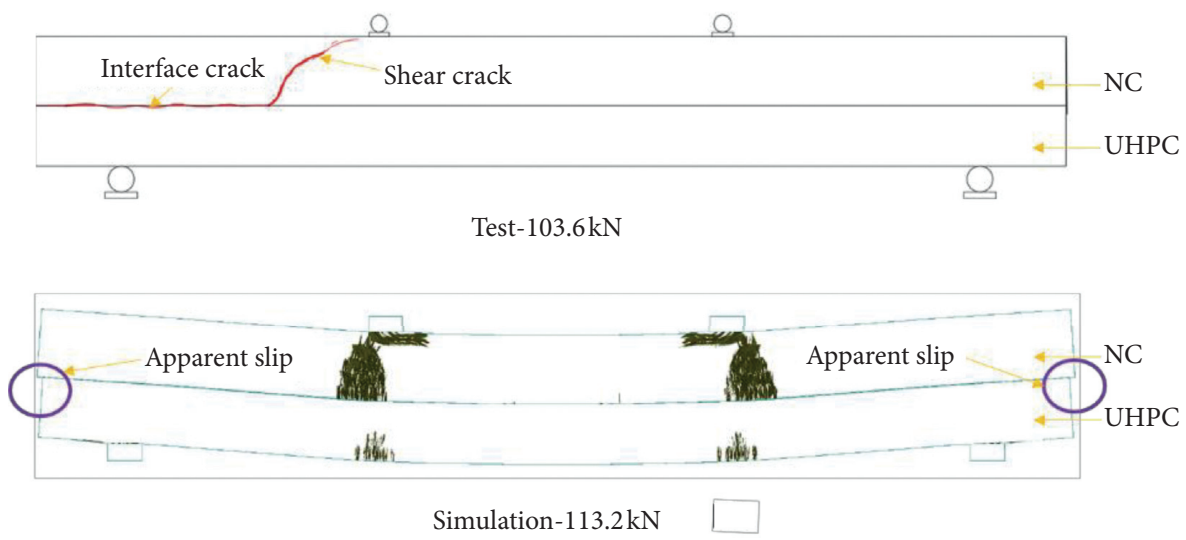

(c)

FIgURE 24: Continued. 

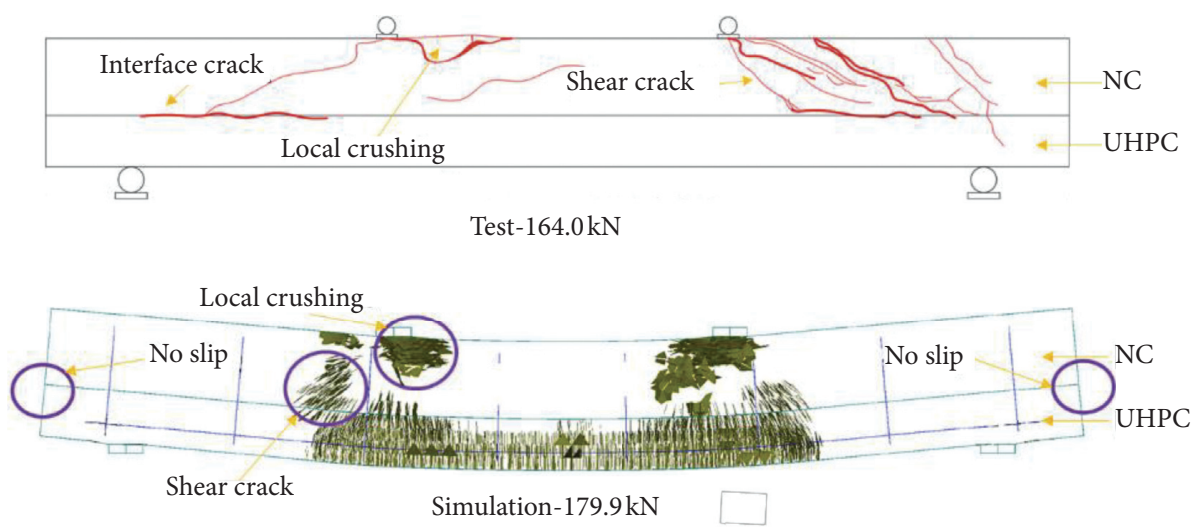

(d)

FIGURE 24: Experimental and numerical comparisons of failure modes. (a) Specimen U50. (b) Specimen U60. (c) Specimen U70. (d) Specimen U60-LS.

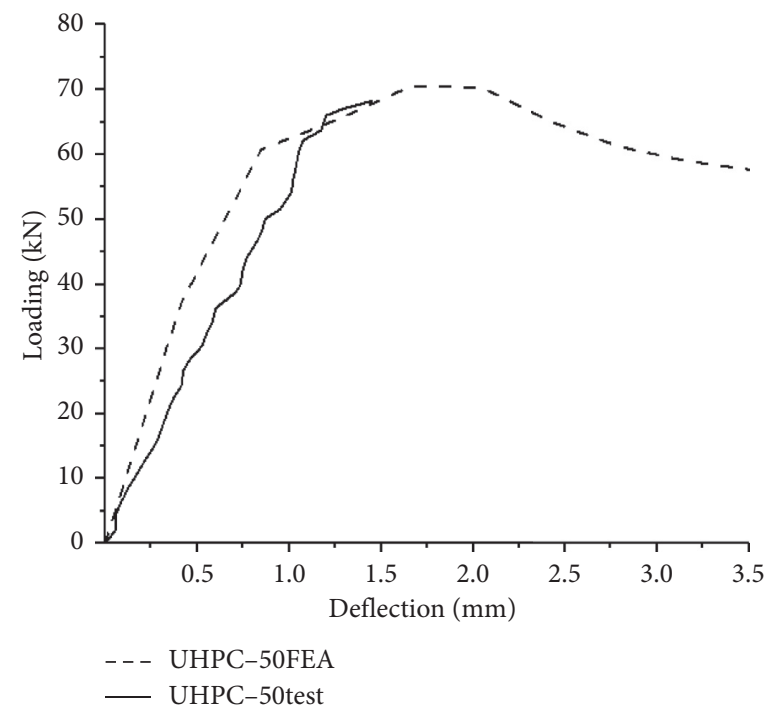

(a)

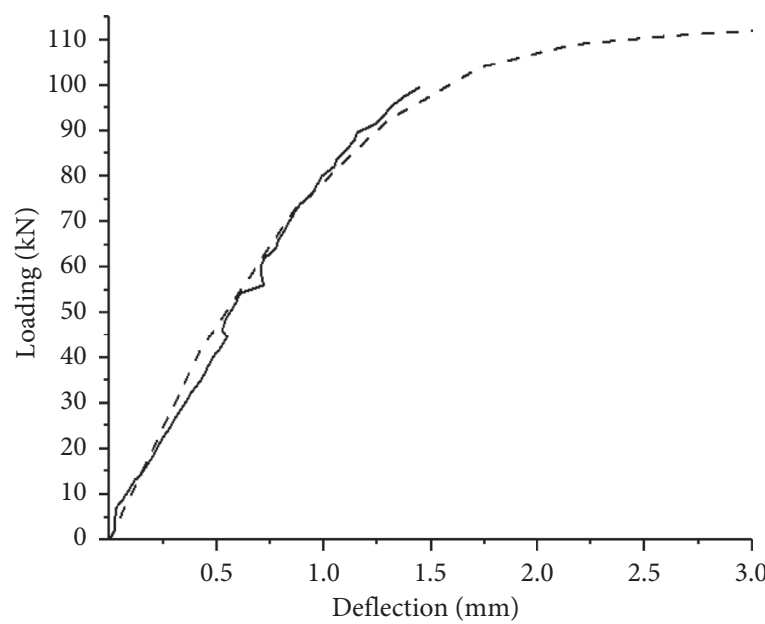

- - - UHPC-70FEA

_ UHPC-70test

(c)

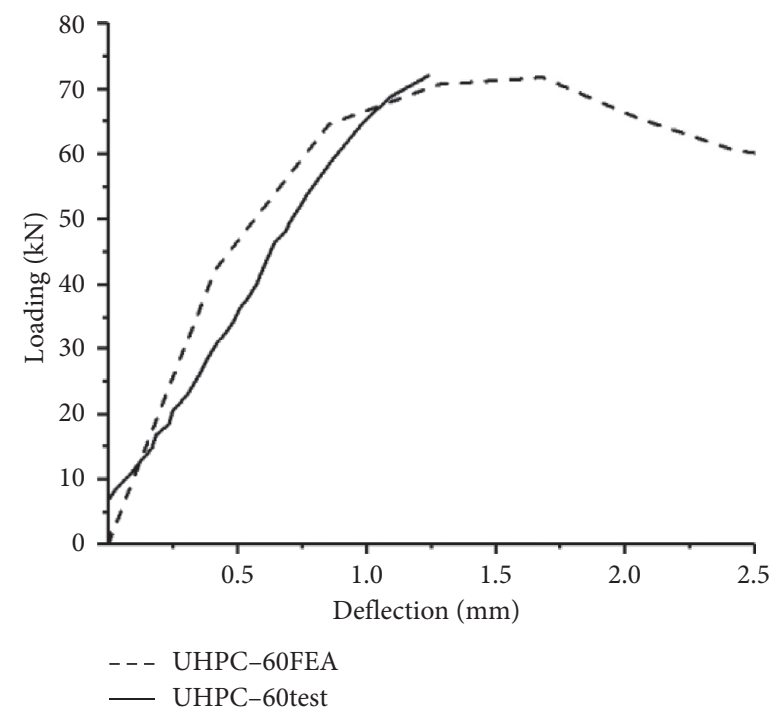

(b)

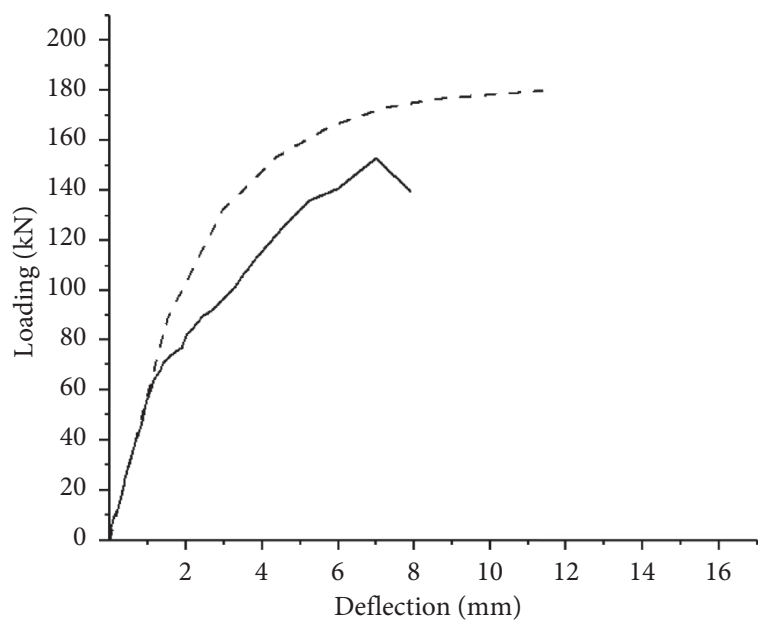

- - - UHPC-60LSFEA

_ UHPC-60LStest

(d)

Figure 25: Experimental and numerical comparisons of loading-deflection curves. (a) Specimen U50. (b) Specimen U60. (c) Specimen U70. (d) Specimen U60-LS. 
$70.6 \mathrm{kN}$ for specimen $\mathrm{U} 50,76.9 \mathrm{kN}$ vs $71.7 \mathrm{kN}$ for specimen $\mathrm{U} 60,103.6 \mathrm{kN}$ vs $113.2 \mathrm{kN}$ for specimen $\mathrm{U} 70$, and $164 \mathrm{kN}$ vs $179.9 \mathrm{kN}$ for specimen U60-LS. The agreements validate the effectiveness of the $3 \mathrm{D}$ FE model in capturing structural behaviors of the NC-UHPC composite slabs.

\section{Conclusion}

Based on the experimental and numerical results, the following conclusions can be drawn:

(1) For the composite decks wo any longitudinal or transverse rebars, the UHPC substrate could increase the peak strength and stiffness and affect the deformation capacity. Interestingly, the UHPC substrate can even alter the failure mode of the composite deck, from flexural failure for specimen with thinner UHPC substrate to shear failure for specimen with thicker UHPC substrate.

(2) The incorporation of merely transverse rebars seems to impair the flexural capacity of composite decks wo longitudinal rebars, as they would weaken the composite cross section.

(3) For the composite decks typically reinforced with both longitudinal and transverse rebars, the UHPC substrate could apparently increase the cracking and peak strengths. Of special attention is that the agreed post-peak UHPC material renders the NC overlay susceptible to the crushing

(4) Although having been reported with satisfied bond behaviors, the failure of the NC-UHPC interface is still possible for the composite decks wo any longitudinal or transverse rebars.

(5) The analytical solutions to predict the composite deck's strength are derived, either flexural or shear strengths. The plane section assumption verified by the test serves as the basis for the analytical solutions.

(6) The 3D FE models within the ATENA framework are constructed for composite decks. With the NC-UHPC interface behavior being experimentally obtained and taken into account, the numerical models can realistically capture the composite decks' static behaviors.

The investigation serves as a pilot study of the novel composite deck system $w / w o$ rebars, of which the UHPC substrate serves as the NC overlay's formwork. This composite system is expected to benefit the future $A B C$ of newly built bridge decks.

\section{Data Availability}

The data used to support the findings of this study are available from the corresponding author upon request.

\section{Conflicts of Interest}

The authors declare that they do not have any commercial or associative interest that represents any conflicts of interest in connection with the work submitted.

\section{Acknowledgments}

This research was supported by the National Natural Science Foundation (51778137). It was also supported by Shanghai Engineering Research Center of High Performance Composite Bridges (19DZ2254200). The support provided by China Scholarship Council (CSC) during a visit of the first author to University of Maryland, College Park, is also acknowledged. The authors would also like to thank Professor Xiaoyuan He and his two graduate students Xiangyun Ren and Xiangyang $\mathrm{Xu}$ in Southeast University for their valuable assistance on the DIC technology.

\section{References}

[1] S. H. Park, D. J. Kim, G. S. Ryu, and K. T. Koh, “Tensile behavior of ultra high performance hybrid fiber reinforced concrete," Cement and Concrete Composites, vol. 34, no. 2, pp. 172-184, 2012.

[2] Y. Choi and R. L. Yuan, "Experimental relationship between splitting tensile strength and compressive strength of GFRC and PFRC," Cement and Concrete Research, vol. 35, no. 8, pp. 1587-1591, 2005.

[3] P. Y. Blais and M. Couture, "Precast, prestressed pedestrian bridge world's first reactive powder concrete structure," $P C I$ Journal, vol. 44, no. 5, pp. 60-71, 1999.

[4] Z. Hajar, A. Simon, D. Lecointre, and J. Petitjean, "Construction of the first road bridges made of UHPC Proceedings of the $3^{\text {rd }}$ International Symposium on HPC," Orlando, FL, USA, 2003.

[5] M. A. Saleem, A. Mirmiran, J. Xia, and K. Mackie, "Ultrahigh-performance concrete bridge deck reinforced with highstrength steel," ACI Structural Journal, vol. 108, no. 5, 2011.

[6] S. Aaleti, B. Petersen, and S. Sritharan, Design Guide for Precast UHPC Waffle Deck Panel System, Including Connections: No FHWA-HIF-13-032 United States, Federal Highway Administration, Washington, DC, USA, 2013.

[7] B. Suryanto, K. Nagai, and K. Maekawa, "Heterogeneous fiber-particle composite subjected to principal stress rotation: innovative materials and techniques in concrete construction," 2012.

[8] E. Brühwiler and E. Denarié, "Rehabilitation and strengthening of concrete structures using ultra-high performance fibre reinforced concrete," Structural Engineering International, vol. 23, no. 4, pp. 450-457, 2013.

[9] T. Tong, S. Yuan, W. Zhuo, Z. He, and Z. Liu, "Seismic retrofitting of rectangular bridge piers using ultra-high performance fiber reinforced concrete jackets," Composite Structures, vol. 228, Article ID 111367, 2019.

[10] S. Aaleti, S. Sritharan, D. Bierwagen, and T. J. Wipf, Experimental evaluation of structural behavior of precast UHPC waffle bridge deck panels and connections, Transportation Research Board Annual Meeting, Washington, DC, USA, 2011.

[11] E. Honarvar, S. Sritharan, J. M. Rouse, and S. Aaleti, "Bridge decks with precast UHPC waffle panels: a field evaluation and design optimization," Journal of Bridge Engineering, vol. 21, no. 1, Article ID 04015030, 2015.

[12] E. Fehling, M. Schmidt, J. Walraven, T. Leutbecher, and S. Fröhlich, Ultra-high Performance Concrete UHPC: Fundamentals, Design, Examples, John Wiley \& Sons, Hoboken, NJ, USA, 2014. 
[13] B. A. Graybeal, Behavior of Ultra-High Performance Concrete Connections between Precast Bridge Deck Elements: Concrete Bridge Conference: Achieving Safe, Smart \& Sustainable Bridges, Phoenix, AZ, US, 2010.

[14] L. C. Hoomes, H. C. Ozyildirim, and M. Brown, Evaluation of High-Performance Fiber-Reinforced Concrete for Bridge Deck Connections, Closure Pours, and Joints: No. FHWA/VTRC 17R15, Virginia Transportation Research Council, Charlottesville, VA, USA, 2017.

[15] Z. B. Haber and B. A. Graybeal, "Lap-spliced rebar connections with UHPC closures," Journal of Bridge Engineering, vol. 23, no. 6, Article ID 04018028, 2018.

[16] M. Shafieifar, M. Farzad, and A. Azizinamini, "Experimental and numerical study on mechanical properties of ultra high performance concrete (UHPC)," Construction and Building Materials, vol. 156, pp. 402-411, 2017.

[17] S. Aaleti and S. Sritharan, "Quantifying bonding characteristics between UHPC and normal-strength concrete for bridge deck application," Journal of Bridge Engineering, vol. 24, no. 6, Article ID 04019041, 2019.

[18] H. Yazıc1, "The effect of curing conditions on compressive strength of ultra high strength concrete with high volume mineral admixtures," Building and Environment, vol. 42, no. 5, pp. 2083-2089, 2007.

[19] Z. Su, L. Lu, S. Dong, F. Yang, and X. He, "Auto-calibration and real-time external parameter correction for stereo digital image correlation," Optics and Lasers in Engineering, vol. 121, pp. 46-53, 2019.

[20] X. Shao, M. M. Eisa, Z. Chen, S. Dong, and X. He, "Selfcalibration single-lens $3 \mathrm{D}$ video extensometer for high-accuracy and real-time strain measurement," Optics Express, vol. 24, no. 26, pp. 30124-30138, 2016.

[21] American Association of State Highway and Transportation Officials, Bridge Design Specifications, American Association of State Highway and Transportation Officials, Washington, DC, USA, 2007.

[22] M. L. Guo, Experimental and Theoretical Study on Static Mechanical Performance of RPC-NC Composite Beam, Beijing Jiaotong University, Beijing, China, 2018.

[23] B. A. Graybeal, "Flexural behavior of an ultrahigh-performance concrete i-girder," Journal of Bridge Engineering, vol. 13, no. 6, pp. 602-610, 2008.

[24] F. Baby, P. Marchand, M. Atrach, and F. Toutlemonde, "Analysis of flexure-shear behavior of UHPFRC beams based on stress field approach," Engineering Structures, vol. 56, pp. 194-206, 2013.

[25] C. G. Hovell, Structural Performance of Texas U-Beams at Prestress Transfer and under Shear-Critical Loads, University of Texas at Austin, Austin, Texas, 2011.

[26] V. Cervenka, J. Cervenka, and R. Pukl, "Atena-a tool for engineering analysis of fracture in concrete," Sadhana, vol. 27, no. 4, pp. 485-492, 2002.

[27] F. J. Vecchio and M. P. Collins, "The modified compressionfield theory for reinforced concrete elements subjected to shear," ACI Journal Proceedings, vol. 83, no. 2, pp. 219-231, 1986. 